\title{
A CONVEX COVER FOR CLOSED UNIT CURVES HAS AREA AT LEAST 0.0975
}

\author{
BOGDAN GRECHUK AND SITTICHOKE SOM-AM
}

\begin{abstract}
We combine geometric methods with numerical box search algorithm to show that the minimal area of a convex set on the plane which can cover every closed plane curve of unit length is at least 0.0975 . This improves the best previous lower bound of 0.096694 . In fact, we show that the minimal area of convex hull of circle, equilateral triangle, and rectangle of perimeter 1 is between 0.0975 and 0.09763 .
\end{abstract}

\section{INTRODUCTION}

In 1966, Leo Moser [9] posed a question to determine the smallest area of plane region $S$ which can cover every curve of length 1, assuming that the curve may be translated and rotated to fit inside the region. This problem, known as "Moser's worm problem", remains open, and it is not even known that the smallest-area region with this property exists - an alternative possibility is that the infimum of possible areas of $S$ can not be actually attained. The current record belonging to Norwood and Poole [10], who constructed a (nonconvex) set $S$ with this property and area at most 0.260437 . From the lower bounds perspective, it is known only that area of any such set $S$ must be strictly positive 8 .

Several variants of Moser's worm problem has been studied in the literature. In particular, one can modify:

(1) the allowed covering regions (e.g. triangle, rectangle, convex, non-convex)

(2) the sets of curves to be covered (e.g. closed curves, convex curves)

If one insists for the covering set $S$ to be convex, Laidecker and Poole [7] used Blachke Selection Theorem to show that the solution to Moser's worm problem exists. If $\alpha$ is the area of this smallest convex covering set, it is known that $0.232239 \leq \alpha \leq 0.27091$, where the upper bound was found by Wang [13] in 2006, while the lower bound was proved by Khandhawit, Sriswasdi and Pagonakis [6] in 2013.

This work studies the version of Moser's worm problem, asking for convex region $S$ of minimal area $\beta$, which can cover every closed curve of length 1. H.G. Eggleton [3] proved in 1957 that a triangle covers all closed unit curves if and only if it can cover the circle of perimeter 1 . Therefore, the smallest triangle which covers every closed unit curve is the equilateral triangle of side $\frac{\sqrt{3}}{\pi}$ and area $\frac{3 \sqrt{3}}{4 \pi^{2}} \approx 0.13162$. In 1972, Shaer and Wetzel [11 proved that the smallest rectangle with this property has side lengths $\frac{1}{\pi}$ and $\sqrt{\frac{1}{4}-\frac{1}{\pi^{2}}}$ and area about 0.12274. In 2006, Furedi and Wetzel [5] found a cover in the form of pentagon with area less than 0.11222. Recently, Wichiramala [14] discovered a hexagonal cover with area less than 0.11023 . 
Minimum-area convex cover for a set of curves is, equivalently, the minimumarea convex hull of these curves. In 1973, Chakerian and Klamkin [2] proved that the convex hull of the circle with perimeter 1 and the line segment of length $\frac{1}{2}$ is at least 0.0963275 , thus providing the first lower bound for $\beta$. In 2006, Furedi and Wetzel [5] proved that the convex hull of the circle with perimeter 1 and the $0.0261682 \times 0.4738318$ rectangle is at least 0.0966675 . In 2011, Furedi and Wetzel [5] improved the lower bound by replacing the $0.0261682 \times 0.4738318$ rectangle by curvilinear rectangle. This gives the area of convex hull about 0.096694. Hence, the best published bounds for $\beta$ were, before this work,

$$
0.096694 \leq \beta \leq 0.11023 \text {. }
$$

In an unpublished work, Som-am [12] used the Brass grid search method [1] to show that the minimal-area convex hull of the line segment of length $\frac{1}{2}$, circle with perimeter 1 , and the equilateral triangle with perimeter 1 , is about 0.096905 .

The main result of this paper is the following one.

Theorem 1. Any convex set $S$ on the plane which can cover circle of perimeter 1 , equilateral triangle of perimeter 1 , and rectangle of size $0.0375 \times 0.4625$ (and perimeter 1) has area at least 0.0975 .

Theorem 1 immediately implies that

$$
0.0975 \leq \beta,
$$

which is an improvement comparing the best published lower bound 0.096694, as well as comparing an unpublished lower bound 0.096905 .

If $\beta^{\prime}$ is the minimal area of a set which can cover circle, equilateral triangle, and any rectangle of perimeter 1 , then Theorem 1 states that

$$
0.0975 \leq \beta^{\prime} \leq \beta .
$$

Our computation shows that the actual value of $\beta^{\prime}$ is about

$$
\beta^{\prime} \approx 0.09762742 \text {. }
$$

The bound in Theorem 1 is slightly weaker, because we need some margin to allow rigorous analysis of our numerical algorithms. We also show rigorously that $\beta^{\prime} \leq$ 0.09763. This implies that, to improve lower bound for $\beta$ to 0.09763 and beyond, different approach is required.

This paper is organized as follows. In Section 2, we give some basic definitions, and prove preliminary lemmas by geometric methods. These lemmas, together with the box-search numerical algorithm, are applied for proving Theorem 1 in Section 3 and 4. Some concluding discussion is presented in Section 5.

\section{Geometric analysis}

Assume that $C$ is a circle with radius $r=\frac{1}{2 \pi}, R$ is a rectangle with side $u \times v$ such that $u+v=\frac{1}{2}$ and $u=0.0375$, and $T$ is an equilateral triangle of side $\frac{1}{3}$. Remark that $C, R$, and $T$ are convex polygons in $\mathbb{R}^{2}$. Our aim is to prove that, no matter how $C, R$, and $T$ are placed in $\mathbb{R}^{2}$, the area of their convex hull is at least 0.0975 .

Let $F$ be a regular 500-gon inscribed in the circle, such that the sides of $R$ are parallel to some longest diagonals of $F$. We will call the union $X=F \cup R \cup T$ a 


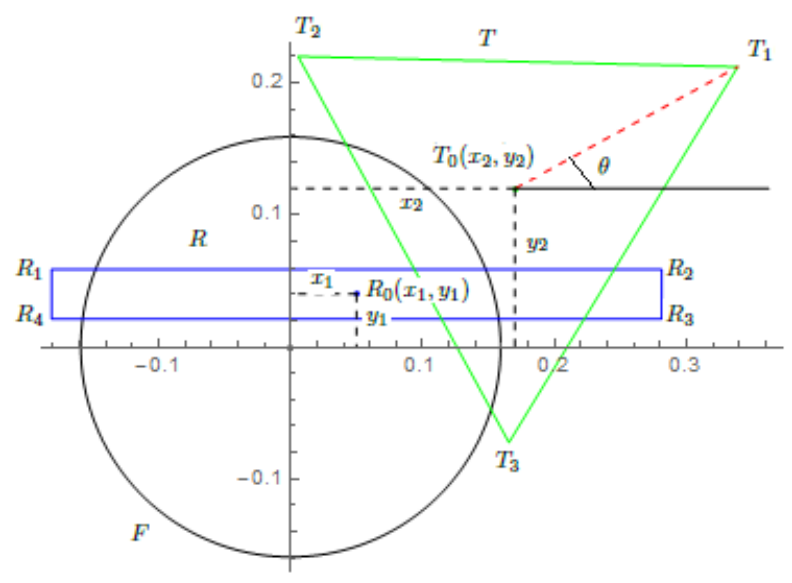

Figure 1. The configuration $X$ which depends on $x_{1}, y_{1}, x_{2}, y_{2}, \theta$

configuration. For any configuration $X$, let $\mathcal{H}(X)$ denote the convex hull of $X$, and $\mathcal{A}(X)$ the area of $\mathcal{H}(X)$.

Let us put a coordinate center $(0,0)$ at the center of $F$, and let $\mathrm{X}$ axis and $\mathrm{Y}$ axis be parallel to the longer and shorter sides of the rectangle, respectively. Let $R_{0}\left(x_{1}, y_{1}\right)$ be the center of $R$. We can orient the axes in such a way that $x_{1} \geq 0$ and $y_{1} \geq 0$. The vertices of $R$ are defined by $R_{1}\left(x_{1}-\left(\frac{\frac{1}{2}-u}{2}\right), y_{1}+\frac{u}{2}\right)$, $R_{2}\left(x_{1}+\left(\frac{\frac{1}{2}-u}{2}\right), y_{1}+\frac{u}{2}\right), R_{3}\left(x_{1}+\left(\frac{\frac{1}{2}-u}{2}\right), y_{1}-\frac{u}{2}\right)$, and $R_{4}\left(x_{1}-\left(\frac{\frac{1}{2}-u}{2}\right), y_{1}-\frac{u}{2}\right)$. Let $T_{0}\left(x_{2}, y_{2}\right)$ be the center of $T$ and $\theta$ be the angle between $\mathrm{X}$ axis and $T_{0} T_{1}$, Then $T_{1}\left(x_{2}+\frac{\sqrt{3}}{9} \cos \theta, y_{2}+\frac{\sqrt{3}}{9} \sin \theta\right), T_{2}\left(x_{2}+\frac{\sqrt{3}}{9} \cos \left(\theta+\frac{2 \pi}{3}\right), y_{2}+\frac{\sqrt{3}}{9} \sin \left(\theta+\frac{2 \pi}{3}\right)\right)$ and $T_{3}\left(x_{2}+\frac{\sqrt{3}}{9} \cos \left(\theta+\frac{4 \pi}{3}\right), y_{2}+\frac{\sqrt{3}}{9} \sin \left(\theta+\frac{4 \pi}{3}\right)\right)$ are the vertices of triangle $T$.

In summary, the location of $F, R$, and $T$ is fully described by 5 parameters: $x_{1}, y_{1}, x_{2}, y_{2}$, and $\theta$.

Let $f: \mathbb{R}^{5} \rightarrow \mathbb{R}$ be a function which maps vector $\left(x_{1}, y_{1}, x_{2}, y_{2}, \theta\right)$ to the area $\mathcal{A}(X)$ of the convex hull of the corresponding configuration $X$. Clearly, $f$ is a continuous function. Because $F$ is a subset of $C$, Theorem 1 would follow from the inequality

$$
f\left(x_{1}, y_{1}, x_{2}, y_{2}, \theta\right)>0.0975, \quad \forall x_{1}, y_{1}, x_{2}, y_{2}, \theta .
$$

The following result of Fary and Redei [4] plays an important role in our analysis

Lemma 2. 4] Let $S_{1}$ and $S_{2}$ be two bounded convex sets in $\mathbb{R}^{2}$. If $S_{1}$ is translated along a line with constant velocity, then the volume of the convex hull of $S_{1}$ and $S_{2}$ is a convex function of time.

Corollary 3. Function $f$ is a convex function in each of the coordinates $x_{1}, y_{1}, x_{2}, y_{2}$.

Proof. Convexity of $f$ with respect to $x_{1}$ follows from Lemma 2 with $S_{2}$ being the convex hull of $F$ and $T$, while $S_{1}=R$ moving along the $\mathrm{X}$ axis. Convexity of $f$ with respect to $y_{1}, x_{2}$, and $y_{2}$ follows from Lemma 2 in a similar way. 
Lemma 4. Let $Z$ be a region of points $z=\left(x_{1}, y_{1}, x_{2}, y_{2}, \theta\right)$ in $\mathbb{R}^{5}$ satisfying the inequalities

$0 \leq x_{1} \leq 0.05,0 \leq y_{1} \leq 0.04,-0.17 \leq x_{2} \leq 0.17,-0.13 \leq y_{2} \leq 0.13,0 \leq \theta \leq \frac{2 \pi}{3}$.

If $f(z)>0.0975$ for all $z \in Z$, then in fact $f(z)>0.0975$ for all $z \in \mathbb{R}^{5}$.

Proof. Let $\psi\left(x_{1}, y_{1}\right)$ be the area of convex hull of $F$ and $R$ only. Lemma 2 implies that $\psi\left(x_{1}, y_{1}\right)$ is a convex function in both coordinates. Assume that $x_{1} \geq 0.05$. By symmetry, $\psi\left(x_{1}, y_{1}\right)=\psi\left(x_{1},-y_{1}\right)$, hence

$$
\psi\left(x_{1}, y_{1}\right) \geq \psi\left(x_{1}, 0\right), \quad \forall x_{1}, y_{1} .
$$

Also, by symmetry, $\psi\left(x_{1}, 0\right)=\psi\left(-x_{1}, 0\right)$, hence convexity of $\psi\left(x_{1}, 0\right)$ implies that $\psi\left(x_{1}, 0\right) \geq \psi(0,0)$, and that $\psi\left(x_{1}, 0\right)$ is non-decreasing in $x_{1}$ for $x_{1} \geq 0$. Hence, $x_{1} \geq 0.05$ implies that

$$
\psi\left(x_{1}, y_{1}\right) \geq \psi\left(x_{1}, 0\right) \geq \psi(0.05,0)>0.0975,
$$

where the last equality is verified directly. For similar reasons,

$$
\psi\left(x_{1}, y_{1}\right) \geq \psi\left(0, y_{1}\right) \geq \psi(0,0.04)>0.0975,
$$

whenever $y_{1} \geq 0.04$.

From symmetry, we may assume that $x_{1} \geq 0$ and $y_{1} \geq 0$. Hence, either $f(z)>$ 0.0975 , or we may assume that $0 \leq x_{1} \leq 0.05$, and $0 \leq y_{1} \leq 0.04$.

Next, assume that $\left|x_{2}\right| \geq 0.17$. Then $\sqrt{x_{2}^{2}+y_{2}^{2}} \geq\left|x_{2}\right| \geq 0.17$. Let $C_{1}$ be the incircle of $T$ with radius $\frac{\sqrt{3}}{18}$ and center $\left(x_{2}, y_{2}\right)$, see Figure 2 .

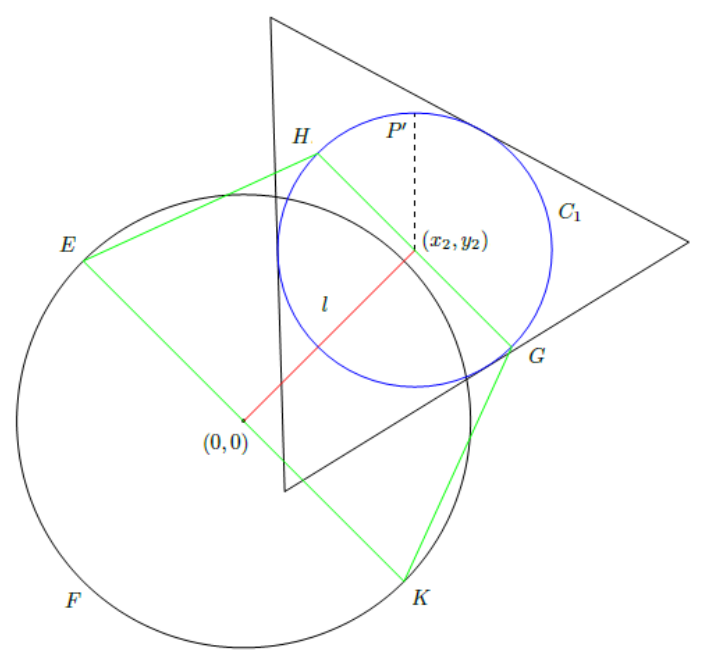

Figure 2. $\mathcal{A}(X)$ is bounded by the area of $E K G H, S(F) / 2$ and the semicircle $C_{1}$

Let $l$ be the line segment between $(0,0)$ and $\left(x_{2}, y_{2}\right)$. Next, let points $H, G \in C_{1}$ and $E, K \in F$ be such that line segments $H G$ and $E K$ are perpendicular to $l$, and pass through $\left(x_{2}, y_{2}\right)$ and $(0,0)$, respectively, see Figure 2 Then $E K G H$ is 
trapezoid with base lengths $|H G|=\frac{\sqrt{3}}{9}$ and $|E K| \geq 2 r \cos \left(\frac{\pi}{500}\right)$, where $r=\frac{1}{2 \pi}$. The area of $F$ is $S(F)=500 \frac{r^{2}}{2} \sin \left(\frac{2 \pi}{500}\right)$. Thus,

$$
\mathcal{A}(X)>\frac{1}{2}\left(2 r \cos \left(\frac{\pi}{500}\right)+\frac{\sqrt{3}}{9}\right)\left(\sqrt{x_{2}^{2}+y_{2}^{2}}\right)+\frac{S(F)}{2}+\frac{\pi\left(\frac{\sqrt{3}}{18}\right)^{2}}{2}>0.0975
$$

To prove the bound for $y_{2}$, we need the following claim.

Claim 1. If there is a point $P^{\prime} \in T$ with $y$-coordinate $y^{*} \geq 0.13+\frac{\sqrt{3}}{18}$, then $f(z)>0.0975$.

Indeed, let $R^{\prime}=(0,-r)$, and $R_{1}, R_{2}, R_{3}, R_{4}$ be the vertices of the rectangle, see Figure 3 .

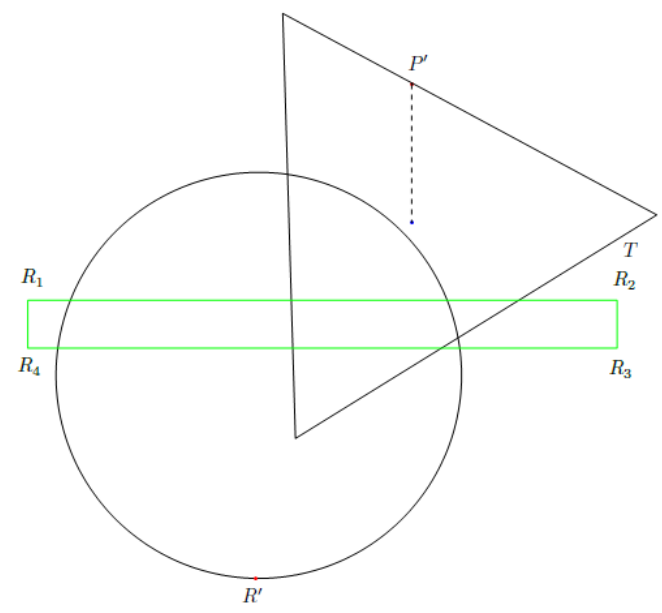

Figure 3. $\mathcal{A}(X)$ is bounded by the area of convex hull of $R^{\prime}, R_{1}, R_{2}, R_{3}, R_{4}$ and $P^{\prime}$

Because $P^{\prime}, R_{1}, R_{2}, R_{3}, R_{4}, R^{\prime} \in \mathcal{H}(X)$, we have $\mathcal{A}(X)>\mathcal{A}\left(\left\{P^{\prime}, R_{1}, R_{2}, R_{3}, R_{4}, R^{\prime}\right\}\right)$ $=u\left(\frac{1}{2}-u\right)+\frac{1}{2}\left(\frac{1}{2}-u\right)\left(\left(y_{2}+\frac{\sqrt{3}}{18}\right)+r-u\right)>0.0975$, and the claim follows.

Now, assume that $y_{2} \geq 0.13$. Let $C_{1}$ be the same circle as above, see Figure 2 and let $P^{\prime}$ be a point on $C_{1}$ with coordinates $\left(x_{2}, y_{2}+\frac{\sqrt{3}}{18}\right)$. Then $P^{\prime} \in T$, and $f(z)>0.0975$ by the claim.

The cases $x_{2} \leq-0.17$ and $y_{2} \leq-0.13$ are considered similarly.

Corollary 5. Either $f(z)>0.0975$, or $F \cup T \cup R$ is a subset of a rectangle with side lengths $0.386 \times 0.644$.

Proof. By Lemma 4, we can assume that $z=\left(x_{1}, y_{1}, x_{2}, y_{2}, \theta\right) \in Z$. Let $Y_{1}$ and $Y_{2}$ be the points of configuration $X=F \cup T \cup R$ with the lowest and highest $y$-coordinates $y_{1}^{*}$ and $y_{2}^{*}$, respectively. Because $0 \leq y_{1} \leq 0.04, Y_{1}$ and $Y_{2}$ cannot belong to the rectangle $R$. If they both belong to $F$, then $y_{2}^{*}-y_{1}^{*}=\frac{1}{\pi}<0.386$. If they both belong to the triangle, then $y_{2}^{*}-y_{1}^{*} \leq \frac{1}{3}<0.386$. If $Y_{1} \in F$ and $Y_{2} \in T$, then $y_{1}^{*}=-\frac{1}{2 \pi}$, and the inequality $y_{2}^{*} \leq 0.13+\frac{\sqrt{3}}{18}$ follows form the Claim 1 in the proof of Lemma 4 Then $y_{2}^{*}-y_{1}^{*} \leq 0.13+\frac{\sqrt{3}}{18}+\frac{1}{2 \pi}<0.386$. 
Similarly, Let $X_{1}$ and $X_{2}$ be the points of configuration $X=F \cup T \cup R$ with the lowest and highest $x$-coordinates $x_{1}^{*}$ and $x_{2}^{*}$, respectively. $z \in Z$ implies that neither $X_{1}$ nor $X_{2}$ belongs to $F$. If $X_{1} \in T$ and $X_{2} \in R$, then, by Lemma $4 x_{1}^{*} \geq-0.17-\frac{\sqrt{3}}{9}$, and $x_{2}^{*} \leq 0.05+\frac{0.4625}{2}$, hence $x_{2}^{*}-x_{1}^{*} \leq 0.05+\frac{0.4625}{2}+0.17+\frac{\sqrt{3}}{9}<0.644$.

The following lemma established Lipschitz continuity of $f$ in $Z$.

Lemma 6. For every $\left(x_{1}, y_{1}, x_{2}, y_{2}, \theta\right) \in Z$, and any $\epsilon_{i} \geq 0, i=1, \ldots, 5$,

$$
\left|f\left(x_{1}+\epsilon_{1}, y_{1}+\epsilon_{2}, x_{2}+\epsilon_{3}, y_{2}+\epsilon_{4}, \theta+\epsilon_{5}\right)-f\left(x_{1}, y_{1}, x_{2}, y_{2}, \theta\right)\right| \leq \sum_{i=1}^{5} \epsilon_{i} C_{i},
$$

with constants $C_{1}=0.212, C_{2}=0.322, C_{3}=0.326, C_{4}=0.398$, and $C_{5}=$ 0.134 .

Proof. If function $g: \mathbb{R} \rightarrow \mathbb{R}$ is convex on $\mathbb{R}$ and

$$
C=\max \left[\lim _{t \rightarrow-\infty} \frac{g(t)}{t}, \lim _{t \rightarrow+\infty} \frac{g(t)}{t}\right]<\infty,
$$

then

$$
|g(t+\epsilon)-g(t)| \leq C \epsilon, \quad \forall t, \forall \epsilon>0 .
$$

Indeed, inequality $C^{\prime}:=\left(g\left(t_{0}+\epsilon\right)-g\left(t_{0}\right)\right) / \epsilon>C$ for some $t_{0}$ and $\epsilon$, would, by convexity of $g$, imply that $g\left(t_{0}+2 \epsilon\right)>g\left(t_{0}\right)+2 C^{\prime} \epsilon$, and, by induction, $g\left(t_{0}+2^{n} \epsilon\right)>$ $g\left(t_{0}\right)+2^{n} C^{\prime} \epsilon$, a contradiction with $\lim _{t \rightarrow+\infty} \frac{g(t)}{t} \leq C<C^{\prime}$. Inequality $\left(g\left(t_{0}+\epsilon\right)-\right.$ $\left.g\left(t_{0}\right)\right) / \epsilon<-C$ leads to a contradiction for similar reasons.

Let us apply this result to convex function $g\left(x_{1}\right)=f\left(x_{1}, y_{1}, x_{2}, y_{2}, \theta\right)$, where $y_{1}, x_{2}, y_{2}, \theta$ are fixed. In this case,

$$
\lim _{x_{1} \rightarrow-\infty} \frac{g\left(x_{1}\right)}{x_{1}}=\lim _{x_{1} \rightarrow+\infty} \frac{g\left(x_{1}\right)}{x_{1}} \leq \frac{0.386+0.0375}{2}<C_{1},
$$

see Figure 4.

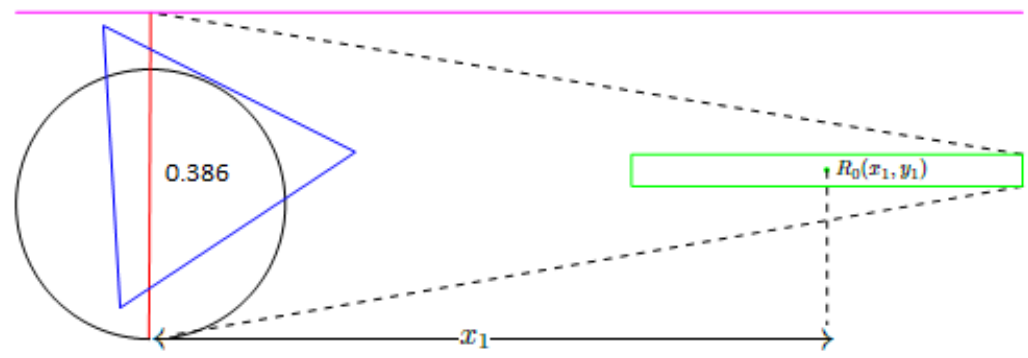

Figure 4 . The ratio between $g\left(x_{1}\right)$ and $x_{1}$ when $x_{1} \rightarrow+\infty$

Hence,

$$
\left|f\left(x_{1}+\epsilon_{1}, y_{1}, x_{2}, y_{2}, \theta\right)-f\left(x_{1}, y_{1}, x_{2}, y_{2}, \theta\right)\right| \leq C_{1} \epsilon_{1} .
$$

Similarly, with $g\left(x_{2}\right)=f\left(x_{1}, y_{1}, x_{2}, y_{2}, \theta\right)$ for fixed $x_{1}, y_{1}, y_{2}, \theta$,

$$
\lim _{x_{2} \rightarrow-\infty} \frac{g\left(x_{2}\right)}{x_{2}}=\lim _{x_{2} \rightarrow+\infty} \frac{g\left(x_{2}\right)}{x_{2}} \leq \frac{2 r+1 / 3}{2}<C_{3},
$$


see Figure 5, while with $g\left(y_{2}\right)=f\left(x_{1}, y_{1}, x_{2}, y_{2}, \theta\right)$,

$$
\lim _{y_{2} \rightarrow-\infty} \frac{g\left(y_{2}\right)}{y_{2}}=\lim _{y_{2} \rightarrow+\infty} \frac{g\left(y_{2}\right)}{y_{2}} \leq \frac{1 / 3+0.4625}{2}<C_{4} .
$$

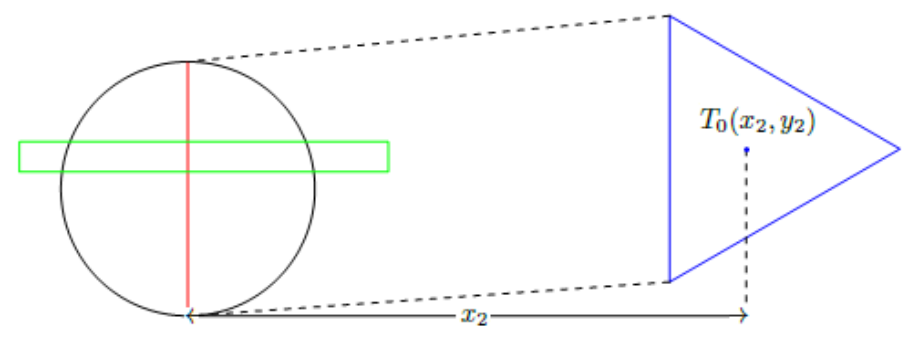

FIGURE 5. The ratio between $g\left(x_{2}\right)$ and $x_{2}$ when $x_{2} \rightarrow+\infty$

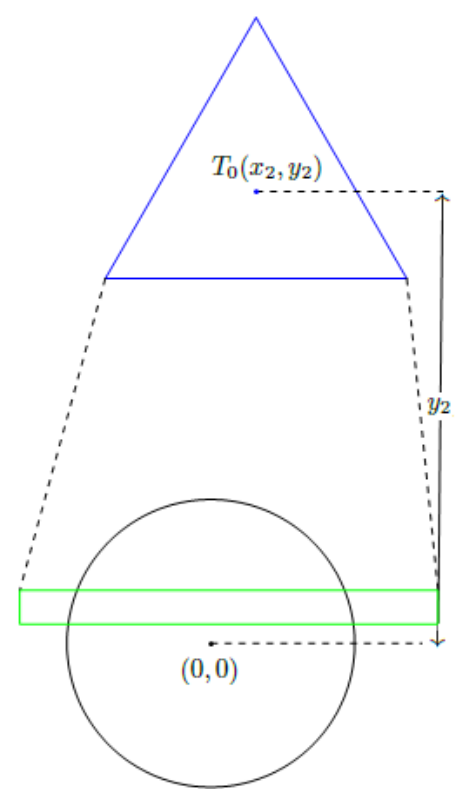

FIGURE 6 . The ratio between $g\left(y_{2}\right)$ and $y_{2}$ when $y_{2} \rightarrow+\infty$

see Figure 6. This implies that

$$
\left|f\left(x_{1}, y_{1}, x_{2}+\epsilon_{3}, y_{2}, \theta\right)-f\left(x_{1}, y_{1}, x_{2}, y_{2}, \theta\right)\right| \leq C_{3} \epsilon_{3},
$$

and

$$
\left|f\left(x_{1}, y_{1}, x_{2}, y_{2}+\epsilon_{4}, \theta\right)-f\left(x_{1}, y_{1}, x_{2}, y_{2}, \theta\right)\right| \leq C_{4} \epsilon_{4} .
$$

The proof of similar bounds for the second and the fifth coordinates requires a different approach. For the second coordinate, we need to prove that

$$
\left|f\left(x_{1}, y_{1}+\epsilon_{2}, x_{2}, y_{2}, \theta\right)-f\left(x_{1}, y_{1}, x_{2}, y_{2}, \theta\right)\right| \leq C_{2} \epsilon_{2} .
$$


We claim that it is sufficient to prove (1) for $\epsilon_{2} \in(0, \epsilon)$ for some $\epsilon>0$, which can depend on $x_{1}, y_{1}, x_{2}, y_{2}$, and $\theta$. Indeed, assume, by contradiction, that, for some $y_{1}$, (1) holds for $\epsilon_{2} \in(0, \epsilon)$ but not for all $\epsilon_{2}>0$. Let $\epsilon^{*}$ be the supremum of all $\epsilon$ such that (1) holds for $\epsilon_{2} \in(0, \epsilon)$. Then, by continuity of $f$, (1) also holds for $\epsilon_{2}=\epsilon^{*}$, that is,

$$
\left|f\left(x_{1}, y_{1}+\epsilon^{*}, x_{2}, y_{2}, \theta\right)-f\left(x_{1}, y_{1}, x_{2}, y_{2}, \theta\right)\right| \leq C_{2} \epsilon^{*} .
$$

Applying (1) to $y_{1}^{\prime}=y_{1}+\epsilon^{*}$, we find that

$$
\left|f\left(x_{1}, y_{1}+\epsilon^{*}+\delta_{2}, x_{2}, y_{2}, \theta\right)-f\left(x_{1}, y_{1}+\epsilon^{*}, x_{2}, y_{2}, \theta\right)\right| \leq C_{2} \delta_{2}
$$

holds for all $\delta_{2} \in(0, \delta)$ for some $\delta>0$. But the last two inequalities imply that (1) holds for all $\epsilon_{2} \in\left(0, \epsilon^{*}+\delta\right)$, a contradiction with the definition of $\epsilon^{*}$.

We next prove (1) for $\epsilon_{2} \in(0, \epsilon)$. Let $R^{\prime}$ with vertices $R_{1}^{\prime} R_{2}^{\prime} R_{3}^{\prime} R_{4}^{\prime}$ be the rectangle $R$ which moved up by $\epsilon_{2}$ in Y-axis's direction. Convex hulls $\mathcal{H}(R, F, T)$ and $\mathcal{H}\left(R^{\prime}, F, T\right)$ are polygons, and, by selecting $\epsilon$ sufficiently small, we can assume that all vertices of these polygons, which are not vertices of $R$ and $R^{\prime}$, coincides. Then $\mathcal{A}\left(R^{\prime}, F, T\right)-\mathcal{A}(R, F, T)$ is bounded by the total area of three triangles, say $R_{1}^{\prime} R_{1} D_{1}, R_{2}^{\prime} R_{2} D_{2}$, and $R_{2}^{\prime} R_{2} T^{*}$ which $D_{1}, D_{2} \in F$ and $T^{*} \in T$ see Figure 7 . Let $h_{1}, h_{2}, h_{3}$ be the height of $R_{1}^{\prime} R_{1} D_{1}, R_{2}^{\prime} R_{2} D_{2}, R_{2}^{\prime} R_{2} T^{*}$, respectively. By Corollary 5. $\left|f\left(x_{1}, y_{1}+\epsilon_{2}, x_{2}, y_{2}, \theta\right)-f\left(x_{1}, y_{1}, x_{2}, y_{2}, \theta\right)\right| \leq \frac{1}{2} \epsilon_{2}\left(h_{1}+h_{2}+h_{3}\right) \leq \frac{1}{2} \epsilon_{2}(0.644)=$ $0.322 \epsilon_{2}=C_{2} \epsilon_{2}$.

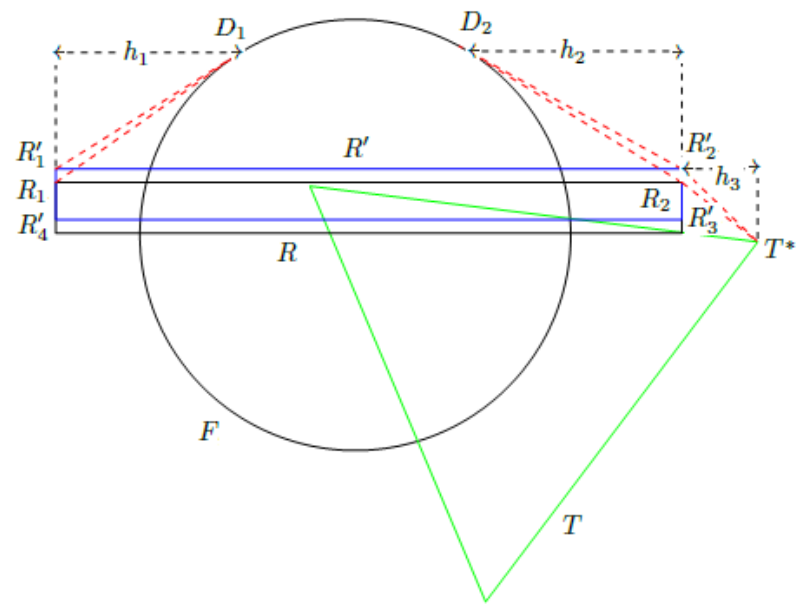

FiguRe 7 . The three triangles which increase the area of convex hull with $\epsilon_{2}$

Finally, we need to prove that

$$
\left|f\left(x_{1}, y_{1}, x_{2}, y_{2}, \theta+\epsilon_{5}\right)-f\left(x_{1}, y_{1}, x_{2}, y_{2}, \theta\right)\right| \leq C_{5} \epsilon_{5} .
$$

To prove the bound for $C_{5}$, we need the following claim.

Claim 2. The diameter $d(\mathcal{F} \cup \mathcal{R})$ of $\mathcal{F} \cup \mathcal{R}$ is less than 0.46402 . 
Indeed, let $R_{0}=(0.05,0.04)$. We get $R_{2}=(0.28125,0.05875)$. Let $F_{1} \in F$ be a point which $d\left(x, R_{2}\right)$ is maximum for all $x \in F$ see Figure 8 . By direct calculation, $R_{2} F_{1}=0.4465<\left|R_{2} R_{4}\right|$. Hence, the diameter of $\mathcal{F} \cup \mathcal{R}$ is $\left|R_{2} R_{4}\right|<0.46402$.

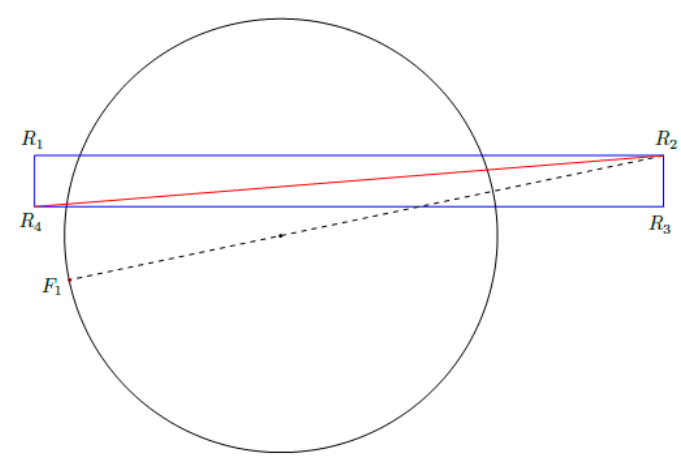

Figure 8 . The longest between $R_{2}$ and $F$

Next, we will prove (2).

Let $T^{\prime}$ with vertices $T_{1}^{\prime}, T_{2}^{\prime}, T_{3}^{\prime}$ be the triangle $T$ rotated around $T_{0}$ by angle $\epsilon_{5}$. Then $\left|T_{1} T_{1}^{\prime}\right|=2\left|T_{0} T_{1}\right| \sin \left(\epsilon_{5} / 2\right)<2\left|T_{0} T_{1}\right|\left(\epsilon_{5} / 2\right)=\left|T_{0} T_{1}\right| \epsilon_{5}=\frac{\sqrt{3}}{9} \epsilon_{5}$. Similarly, $\left|T_{2} T_{2}^{\prime}\right|=\left|T_{3} T_{3}^{\prime}\right|<\frac{\sqrt{3}}{9} \epsilon_{5}$.

By selecting $\epsilon_{5}$ sufficiently small, we can ensure that all vertices of polygons $\mathcal{H}(R, F, T)$ and $\mathcal{H}\left(R, F, T^{\prime}\right)$ coincides, except possibly the vertices of $T$ and $T^{\prime}$.

We assume that no vertices of the triangle $T$ are adjacent in the convex hull of $\mathcal{H}(R, F, T)$. Let $X_{1}$ and $X_{2}$ be the vertices of $\mathcal{H}(R, F, T)$ adjacent to $T_{1}, X_{3}$ and $X_{4}$ - vertices of $\mathcal{H}(R, F, T)$ adjacent to $T_{2}$, and $X_{5}$ and $X_{6}$ - vertices of $\mathcal{H}(R, F, T)$ adjacent to $T_{3}$, see Figure 9. Let us denote $S(A B C)$ the area of any triangle $A B C$.

Then area difference $\left|\mathcal{A}\left(R, F, T^{\prime}\right)-\mathcal{A}(R, F, T)\right|$ is equal to

$\left|\left(S\left(T_{1} X_{1} X_{2}\right)+S\left(T_{2} X_{3} X_{4}\right)+S\left(T_{3} X_{5} X_{6}\right)\right)-\left(S\left(T_{1}^{\prime} X_{1} X_{2}\right)+S\left(T_{2}^{\prime} X_{3} X_{4}\right)+S\left(T_{3}^{\prime} X_{5} X_{6}\right)\right)\right|$. But $\mid\left(S\left(T_{1} X_{1} X_{2}\right)-S\left(T_{1}^{\prime} X_{1} X_{2}\right)|=| \frac{1}{2} h_{1}\left|X_{1} X_{2}\right|-\frac{1}{2} h_{2}\left|X_{1} X_{2}\right|\left|=\frac{1}{2}\right| X_{1} X_{2}|\cdot| h_{1}-h_{2} \mid\right.$, where $h_{1}$ and $h_{2}$ are heights of triangles $T_{1} X_{1} X_{2}$ and $T_{1}^{\prime} X_{1} X_{2}$, respectively, see Figure 10. But $\left|X_{1} X_{2}\right|<0.46402$ by Claim 2, and $\left|h_{1}-h_{2}\right| \leq\left|T_{1} T_{1}^{\prime}\right|<\frac{\sqrt{3}}{9} \epsilon_{5}$, hence $\mid\left(S\left(T_{1} X_{1} X_{2}\right)-S\left(T_{1}^{\prime} X_{1} X_{2}\right) \mid<0.46402 \cdot \frac{\sqrt{3}}{18} \epsilon_{5}\right.$. The same bound holds for $\mid\left(S\left(T_{2} X_{3} X_{4}\right)-S\left(T_{2}^{\prime} X_{3} X_{4}\right) \mid\right.$ and $\mid\left(S\left(T_{3} X_{5} X_{6}\right)-S\left(T_{3}^{\prime} X_{5} X_{6}\right) \mid\right.$. Hence,

$$
\left|\mathcal{A}\left(R, F, T^{\prime}\right)-\mathcal{A}(R, F, T)\right|<3 \cdot 0.46402 \cdot \frac{\sqrt{3}}{18} \epsilon_{5}<0.134 \epsilon_{5}=C_{5} \epsilon_{5} .
$$

\section{Computational Results}

In this section, we use box-search algorithm to prove that the minimal value of function $f(z)=f\left(x_{1}, y_{1}, x_{2}, y_{2}, \theta\right)$ in region $Z$ defined in Lemma 4 is grater than 0.0975 .

In general, let $B$ be a box $\left[a_{1}, b_{1}\right] \times\left[a_{2}, b_{2}\right] \times\left[a_{3}, b_{3}\right] \times\left[a_{4}, b_{4}\right] \times\left[a_{5}, b_{5}\right]$ (that is, set of points $z=\left(x_{1}, y_{1}, x_{2}, y_{2}, \theta\right)$ such that $a_{1} \leq x_{1} \leq b_{1}, a_{2} \leq y_{1} \leq b_{2}, a_{3} \leq x_{2} \leq b_{3}$, 


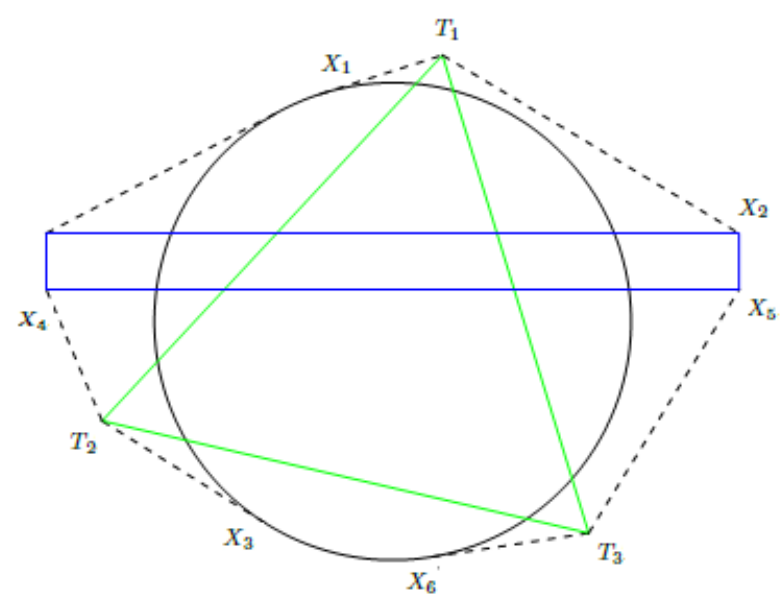

Figure 9. Polygon $\mathcal{H}(R, F, T)$ adjacent $T_{1}, T_{2}, T_{3}$

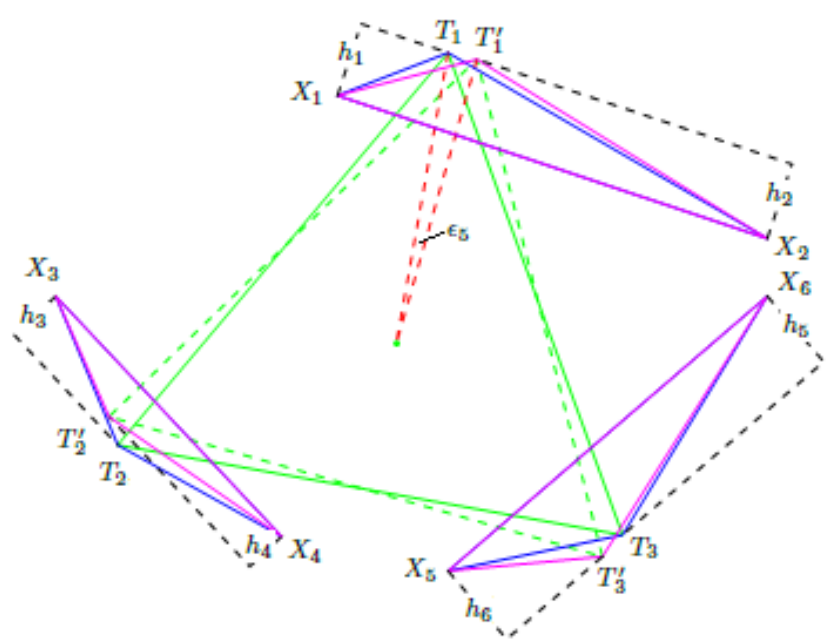

FiguRE 10. Six triangles which $T$ rotated by angle $\epsilon_{5}$

$a_{4} \leq y_{2} \leq b_{4}, a_{5} \leq \theta \leq b_{5}$. Let $z^{*}=\left(\frac{a_{1}+b_{1}}{2}, \frac{a_{2}+b_{2}}{2}, \frac{a_{3}+b_{3}}{2}, \frac{a_{4}+b_{4}}{2}, \frac{a_{5}+b_{5}}{2}\right)$ be the center of the box). Then, if

$$
f\left(z^{*}\right)-d_{1} C_{1}-d_{2} C_{2}-d_{3} C_{3}-d_{4} C_{4}-d_{5} C_{5} \geq 0.0975,
$$

where $d_{i}=\frac{b_{i}-a_{i}}{2}, i=1,2,3,4,5$, then, by Lemma $6, f(z) \geq 0.0975$ for all $z \in B$.

If the condition (3) does not hold for $B$, we will divide $B$ into two sub-boxes $B_{1}$ and $B_{2}$, by dividing its maximal edge by half. For example, if $b_{2}-a_{2} \geq b_{i}-a_{i}$, $i=1,3,4,5$, then edge with length $b_{2}-a_{2}$ is the maximal one, and we divide 
$B$ into $B_{1}=\left[a_{1}, b_{1}\right] \times\left[a_{2},\left(a_{2}+b_{2}\right) / 2\right] \times\left[a_{3}, b_{3}\right] \times\left[a_{4}, b_{4}\right] \times\left[a_{5}, b_{5}\right]$ and $B_{2}=$ $\left[a_{1}, b_{1}\right] \times\left[\left(a_{2}+b_{2}\right) / 2, b_{2}\right] \times\left[a_{3}, b_{3}\right] \times\left[a_{4}, b_{4}\right] \times\left[a_{5}, b_{5}\right]$.

We then check $(3)$ for $B_{1}$ and $B_{2}$. If it holds in both cases, then $f(z) \geq 0.0975$ for all $z \in B_{1}$ and for all $z \in B_{2}$, hence $f(z) \geq 0.0975$ for all $z \in B$. If (3) does not hold for $B_{1}$ (or for $B_{2}$, of for both), we divide the corresponding box by two sub-boxes, and proceed iteratively.

$a_{1}=0, b_{1}=0.05, a_{2}=0, b_{2}=0.04, a_{3}=-0.17, b_{3}=0.17, a_{4}=-0.13, b_{4}=$ $0.13, a_{5}=0, b_{5}=\frac{2 \pi}{3}$. Then we evaluate $f$ in the box center $z^{*}=(0.025,0.02,0,0, \pi / 3)$ to check whether $(3)$ holds. In this case, 3 reduces to

$f\left(z^{*}\right)-\frac{0.05}{2} C_{1}-\frac{0.04}{2} C_{2}-\frac{0.17-(-0.17)}{2} C_{3}-\frac{0.13-(-0.13)}{2} C_{4}-\frac{2 \pi / 3}{2} C_{5}>0.0975$,

or equivalently, to $f\left(z^{*}\right)>0.3567$. However, the computation show that $f\left(z^{*}\right) \approx$ $0.10605<0.3567$, hence $(3)$ does not hold. Hence, we need to subdivide $B$ into $B_{1}$ and $B_{2}$. In this case, $b_{1}-a_{1}=0.05, b_{2}-a_{2}=0.04, b_{3}-a_{3}=0.34, b_{4}-a_{4}=0.26$, and $b_{5}-a_{5}=2 \pi / 3 \approx 1.047$. Hence, $b_{5}-a_{5}>b_{i}-a_{i}, i=1,2,3,4$, and we divide $B$ into $B_{1}=\left[a_{1}, b_{1}\right] \times\left[a_{1}, b_{2}\right] \times\left[a_{3}, b_{3}\right] \times\left[a_{4}, b_{4}\right] \times\left[a_{5},\left(a_{5}+b_{5}\right) / 2\right]$ and $B_{2}=\left[a_{1}, b_{1}\right] \times\left[a_{1}, b_{2}\right] \times\left[a_{3}, b_{3}\right] \times\left[a_{4}, b_{4}\right] \times\left[\left(a_{5}+b_{5}\right) / 2, b_{5}\right]$. Then we repeat the above procedure for $B_{1}$ and for $B_{2}$, and proceed iteratively.

We use Matlabß R2016a to implement this algorithm, see Algorithm 1. The actual Matlab code is presented in the Appendix.

The programme successfully verified the inequality $f(z)>0.0975$ for all $z \in Z$ after $n=7,180,439,126$ iterations. The program actually returned the minimal area 0.09762 for the optimal configuration with $x_{1}=0.0251, y_{1}=0.00258, x_{2}=$ $0.0653, y_{2}=0.00542, \theta=0.07989$ see Figure 11 and Table 14 .

Repeating the calculation for this particular configuration in Mathematica with actual circle instead of 500-gon shows that the optimal convex hull area is about

$$
S_{\text {min }} \approx 0.09762742 \text {. }
$$

\section{Main Theorems}

Theorem. (Theorem 1 in the Introduction) Any convex set $S$ on the plane which can cover circle of perimeter 1 , equilateral triangle of perimeter 1 , and rectangle of size $0.0375 \times 0.4625$ (and perimeter 1 ) has area at least 0.0975 .

Proof. By numerical results, $f(z)>0.0975$ for all $z \in Z$, where $Z$ is defined in Lemma 4. By Lemma 4. this implies that $f(z)>0.0975$ for all $z \in \mathbb{R}^{5}$, hence $\mathcal{A}(F, R, T)>0.0975$. Because 500 -gon $F$ is the subset of circle $C, \mathcal{A}(C, R, T) \geq$ $\mathcal{A}(F, R, T)>0.0975$.

Corollary 7. Any convex cover for closed unit curves has area of at least 0.0975.

Proof. Because every convex cover for closed unit curves should cover the circle $C$, equilateral triangle $T$, and rectangle $R$ of size $0.0375 \times 0.4625$, the claim follows from Theorem 1 . 
Function checkmin $\left(a_{1}, b_{1}, a_{2}, b_{2}, a_{3}, b_{3}, a_{4}, b_{4}, a_{5}, b_{5}, a, r, n, B\right)$

Variables: $a_{1}, b_{1}, a_{2}, b_{2}, a_{3}, b_{3}, a_{4}, b_{4}, a_{5}, b_{5}$ - bounds for the box we consider at this iteration. $a$ - the minimal area of the convex hull we have found so far. $r$ - the total area of all boxes for which inequality 3 is verified so far (this variable is needed to control the progress). $n$ - the number of iterations so far. $B=0.0975$ is the lower bound we are proving.

\section{Procedure:}

1: set the coordinates of the box center:

$x_{1}:=\frac{a_{1}+b_{1}}{2}, y_{1}:=\frac{a_{2}+b_{2}}{2}, x_{2}:=\frac{a_{3}+b_{3}}{2}, y_{2}:=\frac{a_{4}+b_{4}}{2}, \theta:=\frac{a_{5}+b_{5}}{2}$

2 : set $d_{1}:=\frac{b_{1}-a_{1}}{2}, d_{2}:=\frac{b_{2}-a_{2}}{2}, d_{3}:=\frac{b_{3}-a_{3}}{2}, d_{4}:=\frac{b_{4}-a_{4}}{2}, d_{5}:=\frac{b_{5}-a_{5}}{2}$ and set $d:=\max \left\{d_{1}, d_{2}, d_{3}, d_{4}, d_{5}\right\}$

3: calculate convex hull area $S$ of the configuration describes by parameters $x_{1}, y_{1}, x_{2}, y_{2}, \theta$ using function cvh: Set $S=\operatorname{cvh}\left(x_{1}, y_{1}, x_{2}, y_{2}, \theta\right)$.

4: if $S<a$ set $a=S$ (update of the minimal area we have found so far)

5: end if;

6: if $S-C_{1} \cdot d_{1}-C_{2} \cdot d_{2}-C_{3} \cdot d_{3}-C_{4} \cdot d_{4}-C_{5} \cdot d_{5}>B$ (this means that this box is verified)

7 : set $r:=r+32 \cdot d_{1} \cdot d_{2} \cdot d_{3} \cdot d_{4} \cdot d_{5} ;($ add area of this box to $r)$

8: set $n=n+1$; (update count for the number of iterations)

9: return;

10: else (this means that 3 does not hold and we should sub-divide box by two boxes and proceed iteratively)

\section{switch $d$ do}

case 1

for $\mathrm{i}=0$ to 1 do

11: $\quad \operatorname{checkmin}\left(a_{1}+d_{1} \cdot i, a_{1}+d_{1} \cdot(i+1), a_{2}, b_{2}, a_{3}, b_{3}, a_{4}, b_{4}, a_{5}, b_{5}, a, r, n, B\right)$

12: $\quad$ end do

13: $\quad$ case 2

14: $\quad$ for $\mathrm{i}=0$ to 1 do

15: $\quad \operatorname{checkmin}\left(a_{1}, b_{1}, a_{2}+d_{2} \cdot i, a_{2}+d_{2} \cdot(i+1), a_{3}, b_{3}, a_{4}, b_{4}, a_{5}, b_{5}, a, r, n, B\right)$

16: end do

17: $\quad$ case 3

18: $\quad$ for $\mathrm{i}=0$ to 1 do

19: $\quad \operatorname{checkmin}\left(a_{1}, b_{1}, a_{2}, b_{2}, a_{3}+d_{3} \cdot i, a_{3}+d_{3} \cdot(i+1), a_{4}, b_{4}, a_{5}, b_{5}, a, r, n, B\right)$

20: $\quad$ end do

21: $\quad$ case 4

22: $\quad$ for $\mathrm{i}=0$ to 1 do

23: $\quad \operatorname{checkmin}\left(a_{1}, b_{1}, a_{2}, b_{2}, a_{3}, b_{3}, a_{4}+d_{4} \cdot i, a_{4}+d_{4} \cdot(i+1), a_{5}, b_{5}, a, r, n, B\right)$

24: $\quad$ end do

25: $\quad$ case 5

26: for $\mathrm{i}=0$ to 1 do

27: $\quad \operatorname{checkmin}\left(a_{1}, b_{1}, a_{2}, b_{2}, a_{3}, b_{3}, a_{4}, b_{4}, a_{5}+d_{5} \cdot i, a_{5}+d_{5} \cdot(i+1), a, r, n, B\right)$

28: $\quad$ end do

29: $\quad$ end switch

30: end if;

31: if $\operatorname{rem}(\mathrm{n}, 1000000)==0$ print $r / 100$ and $n$ (once in million iterations display the progress so far: for what percentage of the initial box the inequality 3 is verified).

32: end if;

end Procedure

Algorithm 1: Box search algorithm 


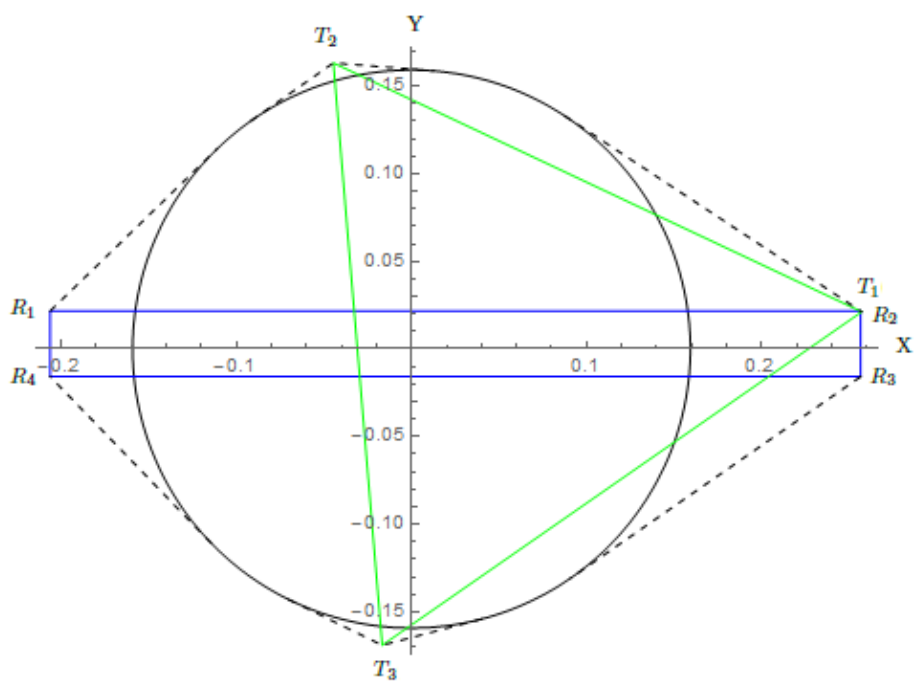

FiguRE 11. The convex hull of the configuration of the minimum area with 0.097627 acquired from the box-search algorithm

The following Theorem implies that this method (with circle, equilateral triangle, and rectangle of perimeter 1) cannot be used to improve the lower bound in Corollary 7 beyond 0.09763 .

Theorem 8. For any rectangle $R^{\prime}$ with perimeter 1 , there is a convex cover of $R^{\prime}$, $C$, and $T$ with area at most 0.09763 .

Proof. Let $l, w$ be the length and width of rectangle $R^{\prime}$ such that $l+w=\frac{1}{2}$ and $w \in[0,0.25]$.

Let $F^{\prime}$ be the regular 500-gon inscribed into the circle with $r^{\prime}=\frac{\sec \left(\frac{\pi}{500}\right)}{2 \pi}$. Then $C \subset F^{\prime}$, and $\mathcal{H}(X)=\mathcal{H}(R, C, T) \subset \mathcal{H}\left(R, F^{\prime}, T\right)$. Thus, $\mathcal{A}(X) \leq \mathcal{A}\left(R, F^{\prime}, T\right)$.

Let $f(w)$ denotes the minimal area of convex cover $R, F^{\prime}, T$.

Claim For any $\epsilon>0,|f(w+\epsilon)-f(w)| \leq 0.318 \epsilon$.

It suffices to prove the claim only for "small" $\epsilon$. We will prove that $f(w)-f(w+\epsilon) \leq$ $0.318 \epsilon$, the proof for inequality $f(w+\epsilon)-f(w) \leq 0.318 \epsilon$ is similar. Let $R^{\prime \prime}$ be the rectangle with width $w+\epsilon$ and perimeter 1 . Consider optimal configuration of $R^{\prime \prime}, F^{\prime}, T$, so that $f(\omega+\epsilon)=\mathcal{A}\left(R^{\prime \prime}, F^{\prime}, T\right)$. Let us put $R^{\prime}$ parallel to $R^{\prime \prime}$ as shown on Figure 12. This configuration is not necessary optimal, and, because $f$ denotes the area of the optimal configuration, $f(w) \leq \mathcal{A}\left(R^{\prime}, F^{\prime}, T\right)$. Hence, $f(w)-f(w+\epsilon) \leq \mathcal{A}\left(R^{\prime}, F^{\prime}, T\right)-\mathcal{A}\left(R^{\prime \prime}, F^{\prime}, T\right)$.

Convex hulls $\mathcal{H}\left(R^{\prime}, F^{\prime}, T\right)$ and $\mathcal{H}\left(R^{\prime \prime}, F^{\prime}, T\right)$ are polygons, and, by selecting $\epsilon$ sufficiently small, we can assume that all vertices of these polygons, which are not vertices of $R^{\prime}$ and $R^{\prime \prime}$, coincides. Then $\mathcal{A}\left(R^{\prime}, F^{\prime}, T\right)-\mathcal{A}\left(R^{\prime \prime}, F^{\prime}, T\right)$ is bounded by the total area of triangles $X Q_{1} R_{2}, Y Q_{2} R_{3}$, and rectangle $Q_{1} R_{2} R_{3} Q_{2}$, which is

$$
\frac{1}{2} h_{1} \epsilon+\frac{1}{2} h_{2} \epsilon+Q_{1} Q_{2} \epsilon=\frac{\epsilon}{2}\left(h_{1}+h_{2}+2 Q_{1} Q_{2}\right)
$$

We have $Q_{1} Q_{2}=w \leq 0.25$, and, by Corollary 5 , $h_{1}+h_{2}+Q_{1} Q_{2} \leq 0.386$. Hence,

$$
f(w)-f(w+\epsilon) \leq \mathcal{A}\left(R^{\prime}, F^{\prime}, T\right)-\mathcal{A}\left(R^{\prime \prime}, F^{\prime}, T\right) \leq \frac{\epsilon}{2}(0.386+0.25)=0.318 \epsilon,
$$


which proves the claim.

To verify inequality $f(w)<0.09763$ at some specific point $w$, it is not necessary to find the optimal configuration of $R^{\prime}, F^{\prime}$, and $T$. In suffices just to find some configuration with $\mathcal{A}\left(R^{\prime}, F^{\prime}, T\right)<0.09763$, and then conclude that $f(w) \leq \mathcal{A}\left(R^{\prime}, F^{\prime}, T\right)<0.09763$. This makes the numerical verification simple.

We will verify inequality $f(w)<0.09763$ for $w$ belonging to some finite set $W=$ $\left\{w_{1}, w_{2}, \ldots, w_{N}\right\}$, where $0 \leq w_{1} \leq w_{2} \leq \cdots \leq w_{N} \leq 0.25$ are points to be specified below. By the claim, inequality $f\left(w_{i}\right)<0.09763$ implies that $f(w) \leq 0.09763$ in the whole interval $w \in\left[w_{i}-d_{i}, w_{i}+d_{i}\right]$, where $d_{i}=\left(0.09763-f\left(w_{i}\right)\right) / 0.318$.

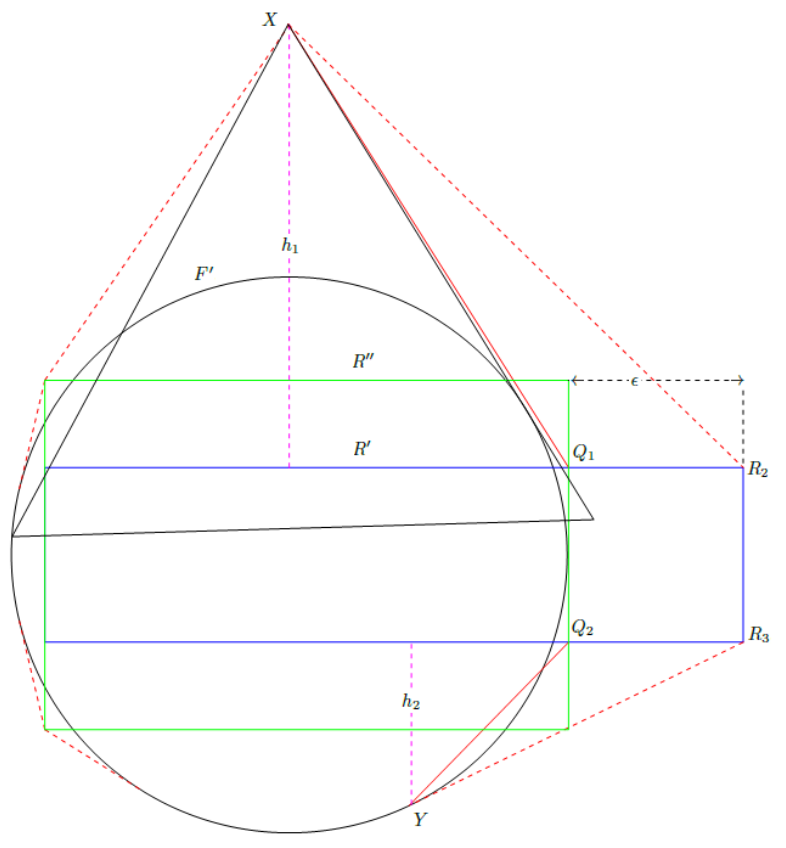

Figure 12. The configuration of $R$ and $R^{\prime}$

We will select set $W$ in such a way that intervals $\left[w_{i}-d_{i}, w_{i}+d_{i}\right], i=1,2, \ldots, N$ cover the whole interval [0,0.25]. In other words, $w_{1}-d_{1}<0, w_{N}+d_{N}>0.25$, and

$$
w_{i}+d_{i}<w_{i+1}-d_{i+1}, \quad i=1,2, \ldots, N-1 .
$$

Set $W$ with $N=772$ points with this property is presented in the Appendix. For example, $w_{1}=0.00020, w_{2}=0.0034, w_{3}=0.0086$, and so on, $w_{772}=0.2415$.

\section{Conclusion And FUture WORK}

Using the method proposed in [12, we improved the lower bound of convex covers for closed unit curves from 0.096694 to 0.0975 . The method is based on studying configurations of the regular 500-gon, rectangle, and equilateral triangle. 
The use geometric methods to prove Lipschitz bound for the corresponding function, and then use numerical box-search algorithm to finish the proof. Based on the numerical results, we conjecture that $T_{1}$ and $R_{2}$ coincides in the optimal configuration, see Figure 13. Our numerical results actually imply lower bound 0.09762742, corresponding to the optimal configuration with parameters $x_{1}=0.0255904, y_{1}=$ $0.0013503, x_{2}=0.0653055, y_{2}=0.0050124$ and $\theta=0.0766554$. However, we can formally prove only the weaker bound 0.0975 , using the algorithm which require $n=7,180,439,126$ iterations. By using more powerful computers, the same methods can lead to, for example, bound 0.0976. However, we have proved that one cannot achieve the bound 0.09763 this way. An obvious way to improve the bound would be studying configurations with 4 objects, but this would increase the dimension of the parameter space.

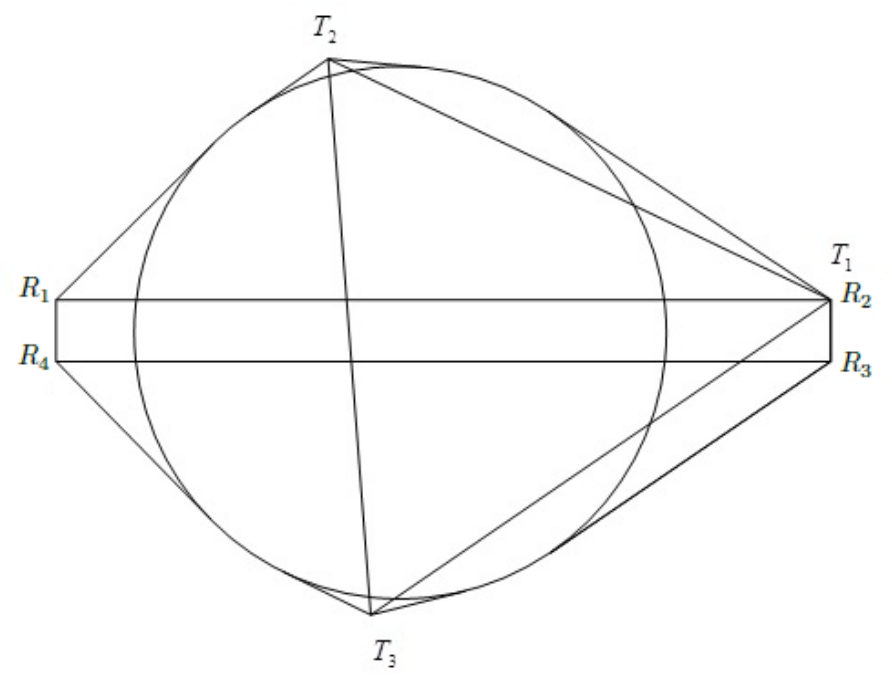

FiguRE 13. The minimum configuration which has an area of 0.09762742 when $T_{1}$ and $R_{2}$ coincide

\section{REFERENCES}

[1] Brass, P., Sharifi, M., A lower bound for Lebesgue's universal cover problem, International Journal of Computational Geometry \& Applications, 15(5), 537-544 (2005)

[2] Chakerian, G.D., Klamkin, M.S., Minimal covers for closed curves, Mathematics Magazine, 46(2), 55-61 (1973)

[3] Eggleston, H.G., Problem in Euclidean space:Application of convexity, 55-61. Courier Corporation, 2007

[4] Fáry, I., Rédei, L., Der zentralsymmetrische Kern und die zentralsymmetrische Hülle von konvexen Körpern, Mathematische Annalen, 122(3), 205-220 (1950)

[5] Füredi, Z., Wetzel, J., Covers for closed curves of length two, Periodica Mathematica Hungarica, 63(1), 1-17 (2011)

[6] Khandhawit, T., Pagonakis, D., Sriswasdi, S., Lower bound for convex hull area and universal cover problems, International Journal of Computational Geometry \& Applications, 23(3), 197-212 (2013)

[7] Laidacker, M., Poole, G., On the existence of minimal covers for families of closed bounded convex sets, Unpublished, 1986

[8] Marstrand, J.M., Packing smooth curves in $R^{q}$, Mathematika, 26(1), 1-12 (1979) 
[9] Moser, L., Poorly formulated unsolved problems of combinatorial geometry, Mimeographed list, 1966

[10] Norwood, R., Poole, G., An improved upper bound for Leo Moser's worm problem, Discrete and Computational Geometry, 29(3), 409-417 (2003)

[11] Schaer, J., Wetzel, J., Boxes for curves of constant length, Israel Journal of Mathematics, 12(3), 257-265 (1972)

[12] Som-am, S., An improved lower bound of areas of convex covers for closed unit arcs, Master's thesis, Chulalongkorn University, 2010

[13] Wang, W., An improved upper bound for worm problem, ACTA MATHEMATICA SINICACHINESE EDITION-, 49(4), 835 (2006)

[14] Wichiramala, W., A smaller cover for closed unit curves, arXiv preprint arXiv:1801.08405. 2018

\section{Appendix A. Appendix}

A.1. Box's search method. Function $\operatorname{cvh}\left(x_{1}, x_{2}, y_{1}, y_{2}, \alpha\right)$ below calculates the area of the convex hull for the configuration defined by parameters $x_{1}, x_{2}, y_{1}, y_{2}, \alpha$. Function checkminNB4 is used to check the main inequality 3 in a box domain defined by its parameters $a_{1}, b_{1}, \ldots, a_{5}, b_{5}$.

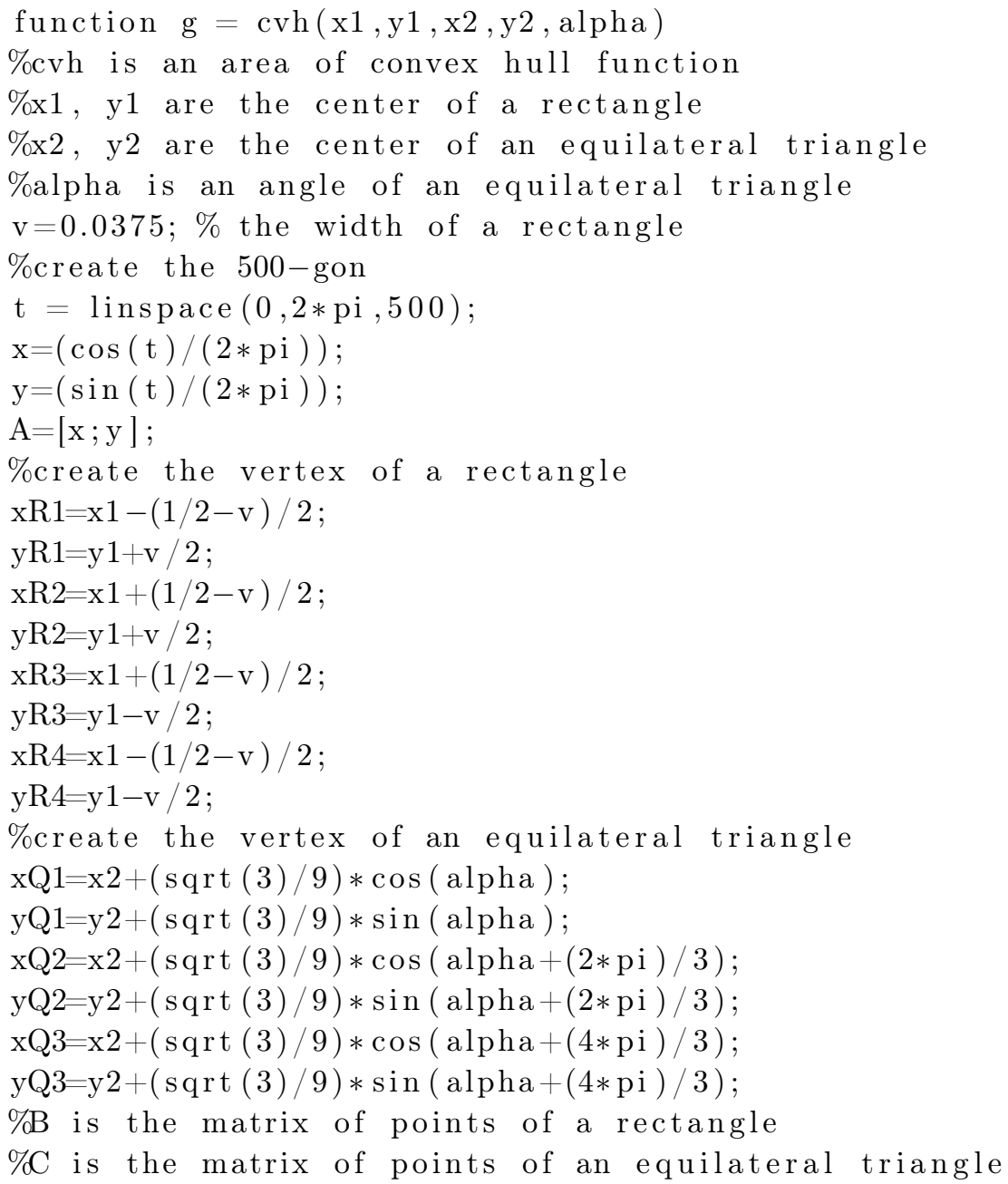


$\%$ is the matrix of points of all objects

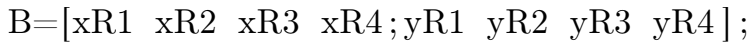

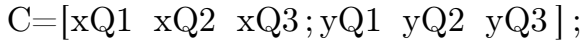

$\mathrm{D}=[\mathrm{A} \quad \mathrm{B} \mathrm{C}]$;

format long

$\% \mathrm{~g}$ is the area of convex hull of $\mathrm{D}$

$[\mathrm{p}, \mathrm{g}]=\mathrm{convhull}(\mathrm{D}(1,:), \mathrm{D}(2,:))$;

end

$(* \quad:$ : Package $:: *)$

function $[\mathrm{r}, \mathrm{n}, \min , \mathrm{xx} 1, \mathrm{yy} 1, \mathrm{xx} 2, \mathrm{yy} 2, \mathrm{app}]=\operatorname{checkminNB} 4(\mathrm{a} 1, \mathrm{~b} 1, \mathrm{a} 2, \mathrm{~b} 2, \mathrm{a} 3$, b3, a4, b4, a5 , b5, s, ep1, area, count, st, ix1, iy1, ix 2, iy 2, iap )

$\%$ checkminNB4 is a function to check the main inequality

$\%$ Input

$\%$ a1 and b1 are a lower bound and an upper bound of $\mathrm{x} 1$

$\%$ a2 and b2 are a lower bound and an upper bound of y1

$\%$ a 3 and b3 are a lower bound and an upper bound of $\mathrm{x} 2$

$\%$ a 4 and b4 are a lower bound and an upper bound of y2

$\%$ a 5 and b5 are a lower bound and an upper bound of alpha

$\% \mathrm{~s}$ is the bound which we want to prove

$\%$ ep1 is tolerant

$\%$ area is a initial area of box (0)

$\%$ count is a initial times which satisfies the main inequality (0)

$\%$ st, ix1, iy 1 , ix 2 , iy 2 and iap are the initial guess of smallest area,

$\% \mathrm{x} 1, \mathrm{y} 1, \mathrm{x} 2, \mathrm{y} 2$ and alpha, respectively.

$\%$ Output

$\% \mathrm{r}$ is a total area of box

$\% \mathrm{n}$ is the number of times which satisfies the main inequality

$\%$ min, $\mathrm{xx} 1, \mathrm{yy} 1, \mathrm{xx} 2, \mathrm{yy} 2$ and aap are the smallest area,

$\% \mathrm{x} 1, \mathrm{y} 1, \mathrm{x} 2, \mathrm{y} 2$ and alpha, respectively.

$\%$ define the box's point

$\mathrm{x} 1=(\mathrm{a} 1+\mathrm{b} 1) / 2$;

$\mathrm{y} 1=(\mathrm{a} 2+\mathrm{b} 2) / 2$;

$\mathrm{x} 2=(\mathrm{a} 3+\mathrm{b} 3) / 2$;

$\mathrm{y} 2=(\mathrm{a} 4+\mathrm{b} 4) / 2$;

alpha $=(\mathrm{a} 5+\mathrm{b} 5) / 2$;

$\mathrm{xx} 1=\mathrm{ix} 1$

yy $1=\mathrm{iy} 1$;

$\mathrm{x} \times 2=\mathrm{i} \times 2$

yу $2=\mathrm{iy} 2$;

app $=\mathrm{iap}$; 


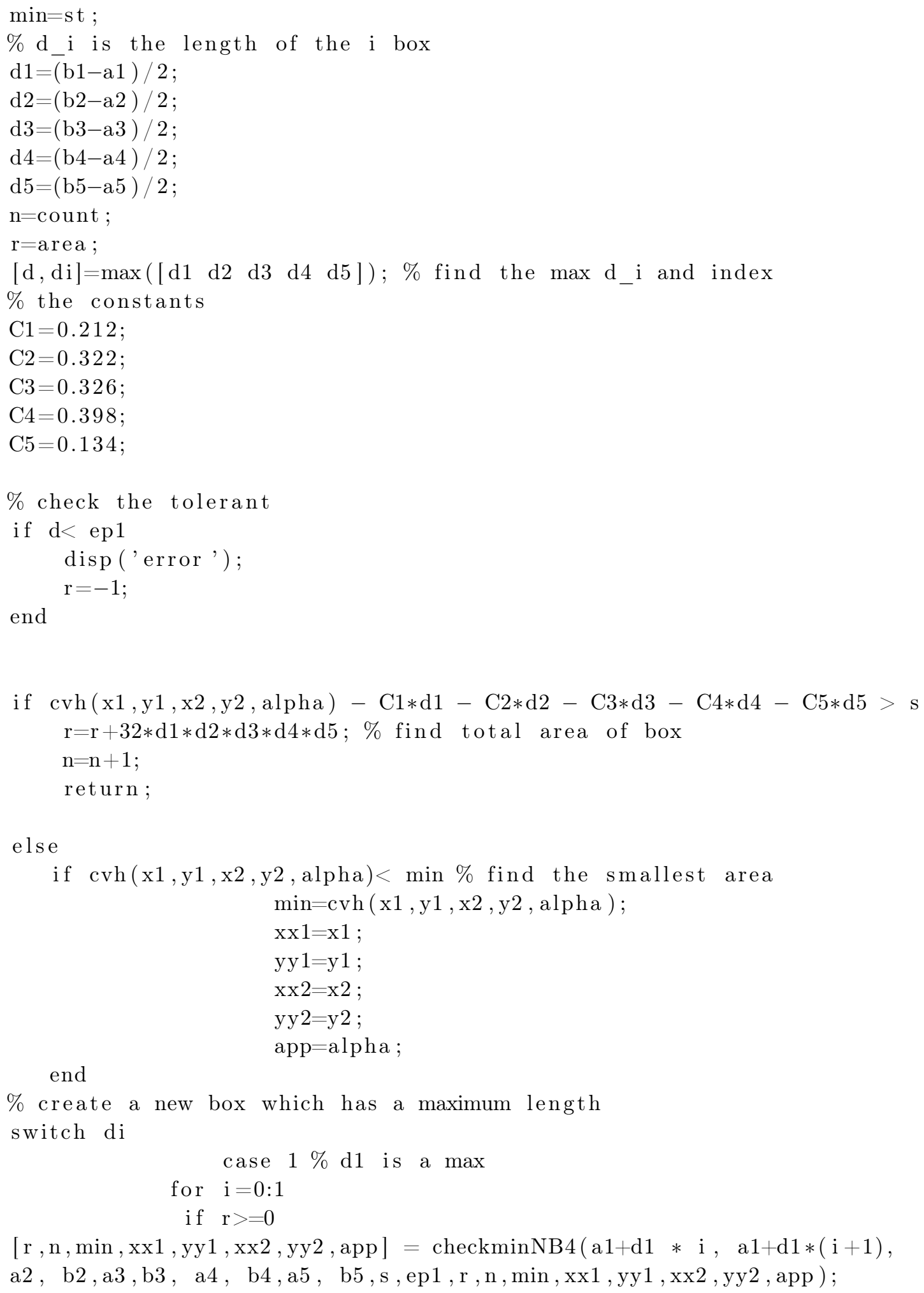

end

$\%$ create a new box which has a maximum length switch di 


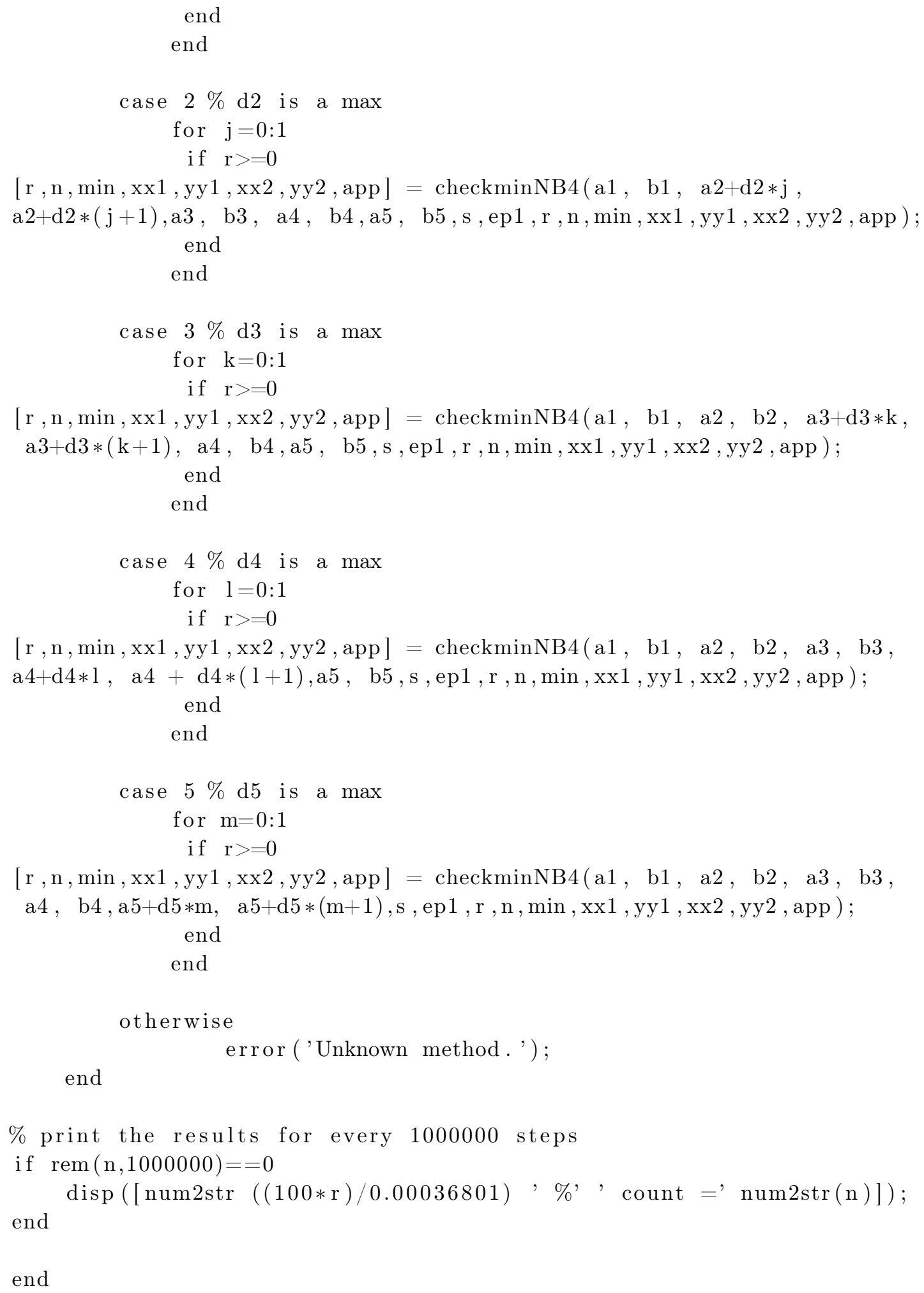


A.1.3. The box's search results. The Box search program displayed a message every 1,000,000 steps. Figure 14 presents the output of these messages for (approximately) every 100,000,000 steps. Here, the first column represents progress, in terms of the percentage of the area of the initial box for which the inequality 3 is verified. The second column is the iteration number. Figure 15 presents the graphical illustration how progress depends on the number of iterations.

When the program finished, it displayed the result:

$\mathrm{r}=3.680103453346938 \mathrm{e}-04$ (this is the area of the initial box, $100 \%$ covered)

$\mathrm{n}=7.180439126000000 \mathrm{e}+09$ (total number of iterations needed)

$\min =0.097626517574902($ the minimal area convex hull)

$\mathrm{xx} 1=0.025097656250000$

yy $1=0.002578125000000$

$\mathrm{xx} 2=0.065327148437500$

yу2 $=0.005422070312500$

app $=0.079894832702377$ (the 5 coordinates for the optimal configuration)

A.2. Matlab program in Theorem 8, Program cvhull2 below calculates the convex hull of the given configuration.

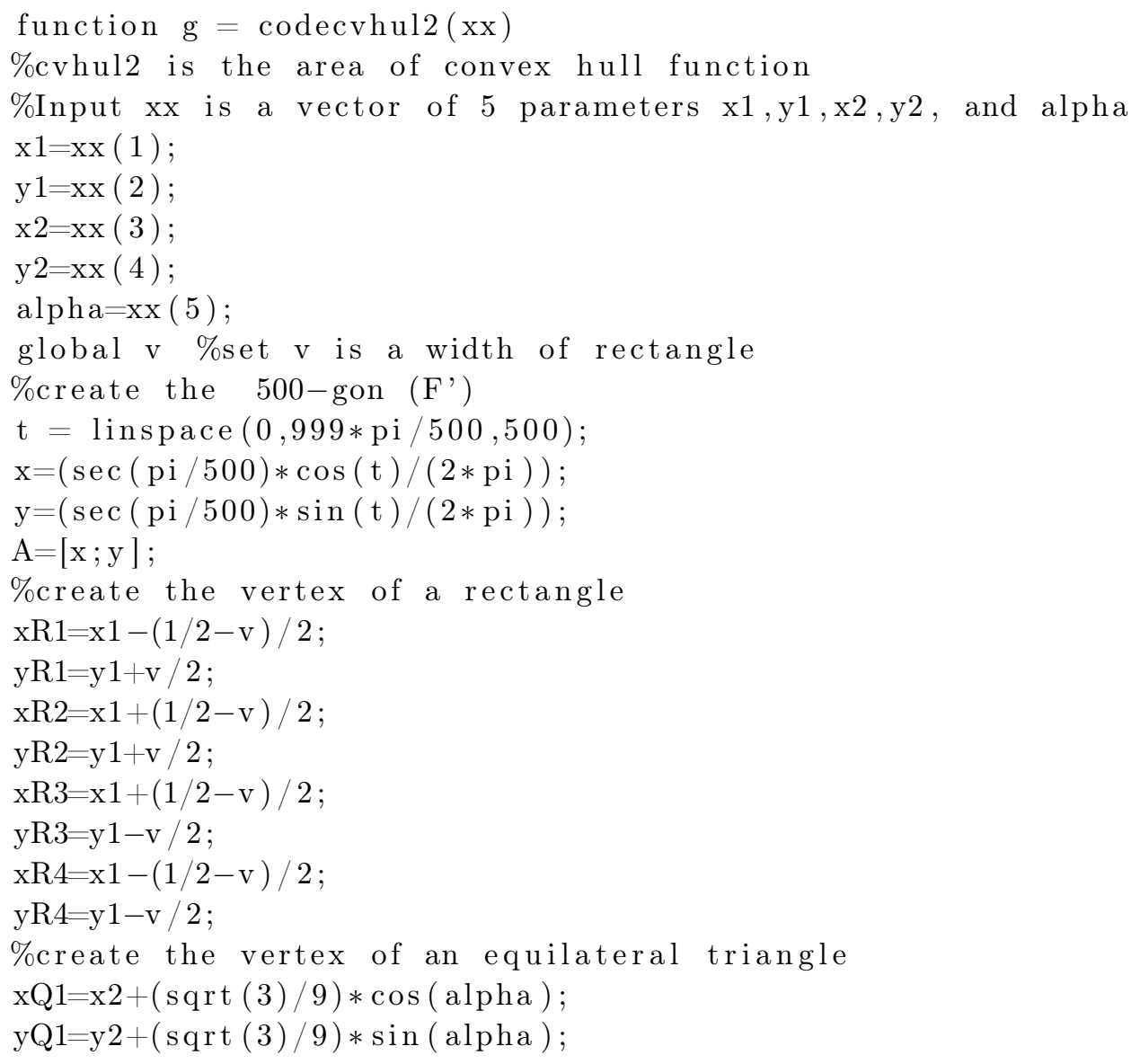


Figure 14. The table of the percentage of $r$ and $n$

\begin{tabular}{|c|c|}
\hline Percentage of $r$ & $n$ \\
\hline \hline $6.5703 \%$ & 100000000 \\
\hline $6.5747 \%$ & 200000000 \\
\hline $6.5762 \%$ & 300000000 \\
\hline $6.5806 \%$ & 400000000 \\
\hline $6.5867 \%$ & 500000000 \\
\hline $6.5882 \%$ & 600000000 \\
\hline $6.6232 \%$ & 702000000 \\
\hline $6.6252 \%$ & 800000000 \\
\hline $6.6375 \%$ & 900000000 \\
\hline $7.0083 \%$ & 1000000000 \\
\hline $7.9108 \%$ & 1100000000 \\
\hline $7.9123 \%$ & 1200000000 \\
\hline $7.9166 \%$ & 1300000000 \\
\hline $7.9167 \%$ & 1400000000 \\
\hline $7.9178 \%$ & 1500000000 \\
\hline $7.9182 \%$ & 1600000000 \\
\hline $7.9182 \%$ & 1700000000 \\
\hline $7.9226 \%$ & 1800000000 \\
\hline $7.9285 \%$ & 1900000000 \\
\hline $7.93 \%$ & 2000000000 \\
\hline $7.93 \%$ & 2100000000 \\
\hline $7.9303 \%$ & 2200000000 \\
\hline $7.9596 \%$ & 2300000000 \\
\hline $7.9611 \%$ & 2400000000 \\
\hline $7.9612 \%$ & 2500000000 \\
\hline $7.9655 \%$ & 2600000000 \\
\hline $7.9655 \%$ & 2700000000 \\
\hline $7.9657 \%$ & 2800000000 \\
\hline $7.967 \%$ & 2900000000 \\
\hline $7.9671 \%$ & 3000000000 \\
\hline $7.9714 \%$ & 3100000000 \\
\hline $7.9773 \%$ & 3200000000 \\
\hline $7.9774 \%$ & 3300000000 \\
\hline $7.9788 \%$ & 3400000000 \\
\hline $7.9789 \%$ & 3500000000 \\
\hline $7.979 \%$ & 3600000000 \\
\hline $8.3014 \%$ & 3700000000 \\
\hline $8.3015 \%$ & 3800000000 \\
\hline $8.3044 \%$ & 3900000000 \\
\hline $8.3073 \%$ & 4000000000 \\
\hline $8.3088 \%$ & 4100000000 \\
\hline $8.3148 \%$ & 4200000000 \\
\hline $8.3191 \%$ & 4300000000 \\
\hline $8.3193 \%$ & 4400000000 \\
\hline $8.3207 \%$ & 4500000000 \\
\hline $8.3502 \%$ & 4600000000 \\
\hline $8.3685 \%$ & 4700000000 \\
\hline $9.6965 \%$ & 4800000000 \\
\hline $97.2442 \%$ & 5900000000 \\
\hline & 500000000 \\
\hline
\end{tabular}




\begin{tabular}{|c|c|}
\hline Percentage of $r$ & $n$ \\
\hline \hline $97.5846 \%$ & 5100000000 \\
\hline $97.5905 \%$ & 5200000000 \\
\hline $97.5964 \%$ & 5300000000 \\
\hline $97.6038 \%$ & 5400000000 \\
\hline $97.6038 \%$ & 5500000000 \\
\hline $97.6334 \%$ & 5600000000 \\
\hline $97.6349 \%$ & 5700000000 \\
\hline $97.6393 \%$ & 5800000000 \\
\hline $97.6408 \%$ & 5900000000 \\
\hline $97.641 \%$ & 6000000000 \\
\hline $97.6511 \%$ & 6100000000 \\
\hline $97.6526 \%$ & 6200000000 \\
\hline $97.6528 \%$ & 6300000000 \\
\hline $97.9265 \%$ & 6400000000 \\
\hline $98.9342 \%$ & 6500000000 \\
\hline $98.9753 \%$ & 6600000000 \\
\hline $98.9769 \%$ & 6700000000 \\
\hline $98.9824 \%$ & 6800000000 \\
\hline $98.9828 \%$ & 6900000000 \\
\hline $98.9931 \%$ & 7000000000 \\
\hline $98.9946 \%$ & 7100000000 \\
\hline
\end{tabular}

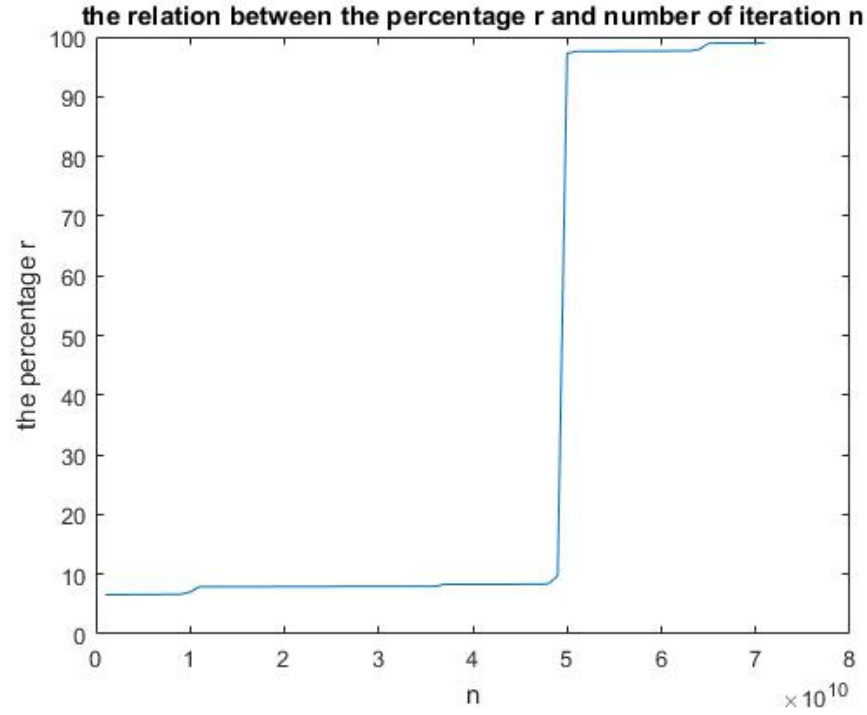

FIGURE 15. The graph of the percentage of $r$ and $n$

$\mathrm{xQ} 2=\mathrm{x} 2+(\operatorname{sqrt}(3) / 9) * \cos (\operatorname{alpha}+(2 * \mathrm{pi}) / 3) ;$

$\mathrm{yQ} 2=\mathrm{y} 2+(\operatorname{sqrt}(3) / 9) * \sin (\operatorname{alpha}+(2 * \mathrm{pi}) / 3)$;

$\mathrm{xQ} 3=\mathrm{x} 2+(\operatorname{sqrt}(3) / 9) * \cos (\operatorname{alpha}+(4 * \mathrm{pi}) / 3)$; 


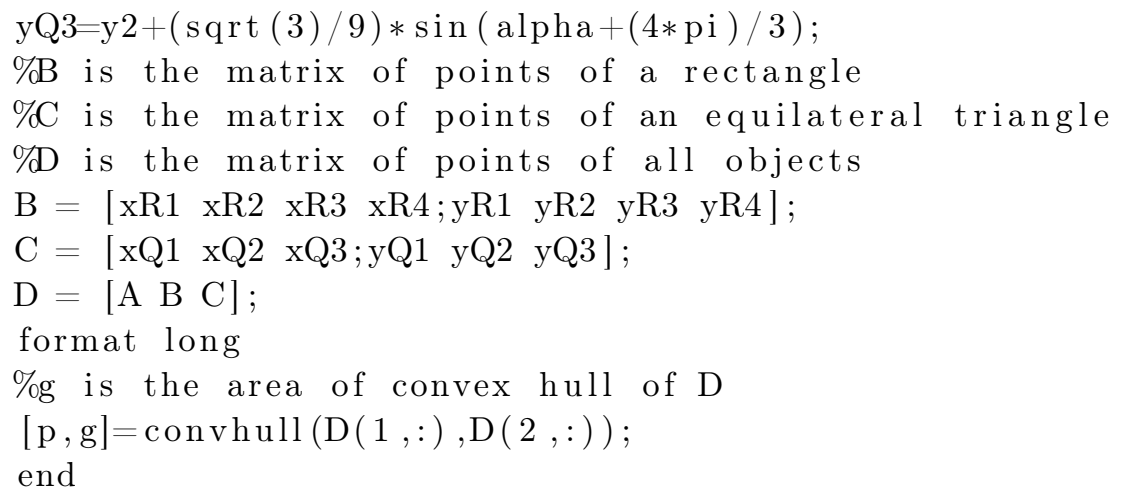

A.2.2. the main program. The function below finds set $W$ which satisfy the condition 4 in the proof of Theorem 8.

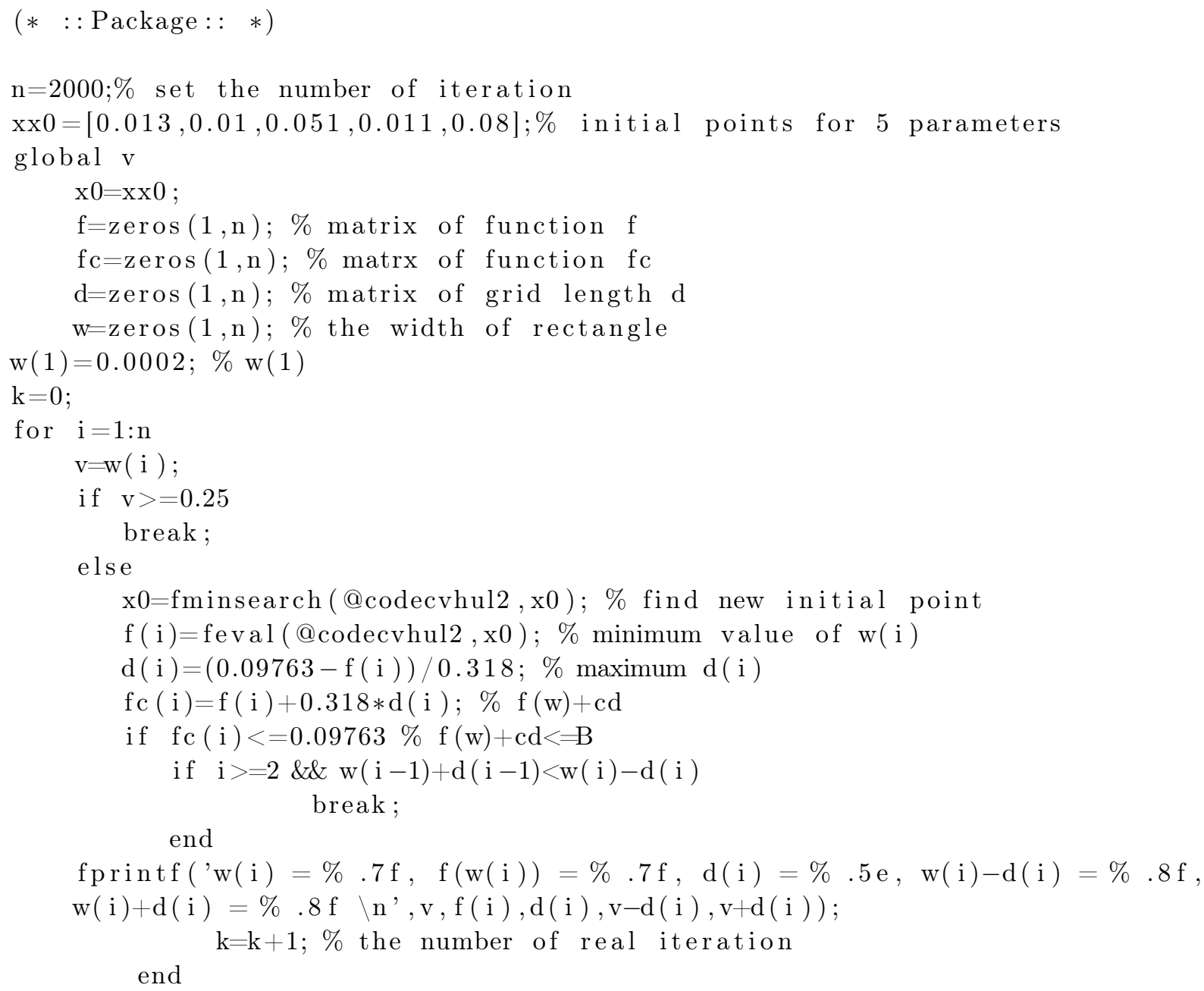


end

$$
\mathrm{w}(\mathrm{i}+1)=\mathrm{w}(\mathrm{i})+1.85 * \mathrm{~d}(\mathrm{i}) ; \% \text { to defind next point }
$$

end

A.2.3. the results. Set $W$ satisfying the condition 4 in the proof of Theorem 8 


\begin{tabular}{|c|c|c|c|c|c|}
\hline $\mathrm{i}$ & $w(i)$ & $f(w(i))$ & $d(i)$ & $w(i)-d(i)$ & $w(i)+d(i)$ \\
\hline 1 & 0.00020 & .09709 & 1.70E-03 & -0.00150 & 0.00190 \\
\hline 2 & 0.00335 & 0.09714 & $1.53 \mathrm{E}-03$ & 0.00183 & 0.00488 \\
\hline 3 & 0.00618 & 0.09721 & $1.33 \mathrm{E}-03$ & 0.00485 & 0.00751 \\
\hline 4 & 0.00864 & 0.09725 & 1.19E-03 & 0.00745 & 0.00983 \\
\hline 5 & 0.01083 & 0.09730 & 1.05E-03 & 0.00978 & 0.01189 \\
\hline 6 & 0.01278 & 0.09734 & $9.25 \mathrm{E}-04$ & 0.01185 & 0.01370 \\
\hline 7 & 0.01449 & 0.09737 & $8.18 \mathrm{E}-04$ & 0.01367 & 0.01531 \\
\hline 8 & 0.01600 & 0.09739 & 7.42E-04 & 0.01526 & 0.01675 \\
\hline 9 & 0.01738 & 0.09742 & 6.60E-04 & 0.01672 & 0.01804 \\
\hline 10 & 0.01860 & 0.09744 & 5.93E-04 & 0.01800 & 0.01919 \\
\hline 11 & 0.01969 & 0.09746 & 5.31E-04 & 916 & 022 \\
\hline 12 & 067 & 0.09748 & 04 & 019 & 115 \\
\hline 13 & 0.02156 & 0.09749 & $4.31 \mathrm{E}-04$ & 0.02113 & 0.02199 \\
\hline 14 & 0.02236 & 0.09751 & 3.89E-04 & 197 & 0.02275 \\
\hline 15 & 0.02308 & 0.09752 & $3.52 \mathrm{E}$ & 273 & 343 \\
\hline 16 & 0.02373 & 0.09753 & 3.20E-04 & 0.02341 & 0.02405 \\
\hline 17 & 0.02432 & 0.09754 & $2.92 \mathrm{E}-04$ & 03 & 162 \\
\hline 18 & 0.02486 & 0.09754 & $2.68 \mathrm{E}-04$ & 0.02460 & 0.02513 \\
\hline 19 & 0.02536 & 0.09755 & $2.46 \mathrm{E}-04$ & 0.02511 & 0.02560 \\
\hline 20 & 0.02581 & 0.09756 & $2.26 \mathrm{E}-04$ & 559 & 604 \\
\hline 21 & 0.02623 & 0.09756 & 2.10E-04 & 0.02602 & 0.02644 \\
\hline 22 & 0.02662 & 0.09757 & $1.94 \mathrm{E}-04$ & 0.02643 & 0.02682 \\
\hline 23 & 0.02698 & 0.09757 & $1.80 \mathrm{E}-04$ & 0.02680 & 2716 \\
\hline 24 & 0.02731 & 0.09758 & $1.68 \mathrm{E}-04$ & 0.02715 & 0.02748 \\
\hline 25 & 0.02762 & 0.09758 & 1.57E-04 & 0.02747 & 0.02778 \\
\hline 26 & 0.02792 & 0.09758 & 1.47E-04 & 2777 & 2806 \\
\hline 27 & 0.02819 & 0.09759 & 1.37E-04 & 0.02805 & 832 \\
\hline 28 & 0.02844 & 0.09759 & $1.30 \mathrm{E}-04$ & 0.02831 & 0.02857 \\
\hline 29 & 0.02868 & 0.09759 & $1.23 \mathrm{E}-04$ & 0.02856 & 0.02880 \\
\hline 30 & 0.02891 & 0.09759 & 1.16E-04 & 0.02879 & 0.02903 \\
\hline 31 & 0.02912 & 0.09760 & 1.10E-04 & 0.02901 & 0.02923 \\
\hline 32 & 0.02933 & 0.09760 & $1.04 \mathrm{E}-04$ & 0.02922 & 0.02943 \\
\hline 33 & 0.02952 & 0.09760 & 9.83E-05 & 0.02942 & 0.02962 \\
\hline 34 & 0.02970 & 0.09760 & 9.35E-05 & 0.02961 & 0.02980 \\
\hline 35 & 0.02988 & 0.09760 & $9.02 \mathrm{E}-05$ & 0.02978 & 0.02997 \\
\hline 36 & 0.03004 & 0.09760 & 8.59E-05 & 0.02996 & 0.03013 \\
\hline 37 & 0.03020 & 0.09760 & 8.20E-05 & 0.03012 & 0.03028 \\
\hline 38 & 0.03035 & 0.09761 & 7.80E-05 & 0.03027 & 0.03043 \\
\hline 39 & 0.03050 & 0.09761 & 7.43E-05 & 0.03042 & 0.03057 \\
\hline 40 & 0.03063 & 0.09761 & 7.07E-05 & 0.03056 & 0.03070 \\
\hline 41 & 0.03077 & 0.09761 & 6.74E-05 & 0.03070 & 0.03083 \\
\hline 42 & 0.03089 & 0.09761 & $6.68 \mathrm{E}-05$ & 0.03082 & 0.03096 \\
\hline 43 & 0.03101 & 0.09761 & $6.42 \mathrm{E}-05$ & 0.03095 & 0.03108 \\
\hline 44 & 0.03113 & 0.09761 & 6.19E-05 & 0.03107 & 0.03119 \\
\hline 45 & 0.03125 & 0.09761 & 5.92E-05 & 0.03119 & 0.03131 \\
\hline 46 & 0.03136 & 0.09761 & $5.68 \mathrm{E}-05$ & 0.03130 & 0.03141 \\
\hline 47 & 0.03146 & 0.09761 & 5.44E-05 & 0.03141 & 0.03152 \\
\hline 48 & 0.03156 & 0.09761 & $5.21 \mathrm{E}-05$ & 0.03151 & 0.03161 \\
\hline
\end{tabular}




\begin{tabular}{|c|c|c|c|c|c|}
\hline $\mathrm{i}$ & $w(i)$ & $f(w(i))$ & $d(i)$ & $w(i)-d(i)$ & $w(i)+d(i)$ \\
\hline 49 & 0.03166 & .09761 & 5.00E-05 & 0.03161 & 0.03171 \\
\hline 50 & 0.03175 & 0.09761 & 4.79E-05 & 0.03170 & .03180 \\
\hline 51 & 0.03184 & 0.09762 & 4.67E-05 & 0.03179 & 0.03189 \\
\hline 52 & 0.03193 & 0.09762 & 4.50E-05 & 0.03188 & 0.03197 \\
\hline 53 & 0.03201 & 0.09762 & 4.33E-05 & 0.03197 & 0.03205 \\
\hline 54 & 0.03209 & 0.09762 & 4.17E-05 & 0.03205 & 0.03213 \\
\hline 55 & 0.03217 & 0.09762 & $\mathrm{E}-05$ & 0.03213 & 0.03221 \\
\hline 56 & 0.03224 & 0.09762 & 3.87E-05 & 0.03220 & 0.03228 \\
\hline 57 & 0.03231 & 0.09762 & 3.77E-05 & 0.03227 & 0.03235 \\
\hline 58 & 0.03238 & 0.09762 & $3.64 \mathrm{E}-05$ & 0.03235 & 0.03242 \\
\hline 59 & 0.03245 & 0.09762 & $3.51 \mathrm{E}-05$ & 0.03241 & 0.03248 \\
\hline 60 & 0.03251 & 0.09762 & 3.39E-05 & 0.03248 & 0.03255 \\
\hline 61 & 0.03258 & 0.09762 & $3.27 \mathrm{E}-05$ & 0.03254 & 0.03261 \\
\hline 62 & 0.03264 & 0.09762 & & 261 & \\
\hline 63 & 0.03270 & 0.09762 & $3.06 \mathrm{E}-05$ & 0.03267 & 0.03273 \\
\hline 64 & 0.03275 & 0.09762 & $2.95 \mathrm{E}-05$ & 0.03272 & 0.03278 \\
\hline 65 & 81 & & & 78 & \\
\hline 66 & 0.03286 & 0.09762 & 2.95E-05 & 0.03283 & 0.03289 \\
\hline 67 & 0.03291 & 0.09762 & 2.8 & 0.03289 & 0.03294 \\
\hline 68 & 0.03297 & & & & \\
\hline 69 & 0.03302 & 0.09762 & 2.71E-05 & 0.03299 & 0.03305 \\
\hline 70 & 0.03307 & 0.09762 & 2.63E-05 & 0.03304 & 0.03310 \\
\hline 71 & 0.03312 & 762 & & 309 & \\
\hline 72 & 0.03317 & 0.09762 & $2.48 \mathrm{E}-05$ & 0.03314 & 0.03319 \\
\hline 73 & 0.03321 & 0.09762 & $2.41 \mathrm{E}-05$ & 0.03319 & 0.03324 \\
\hline 74 & 0.03326 & 62 & & 0.03323 & 0.0 \\
\hline 75 & 0.03330 & 0.09762 & $2.28 \mathrm{E}-05$ & 0.03328 & 0.03332 \\
\hline 76 & 0.03334 & 0.09762 & $2.22 \mathrm{E}-05$ & 0.03332 & 0.03336 \\
\hline 77 & 0.03338 & 0.09762 & $2.15 \mathrm{E}-05$ & 0.03336 & 0.03340 \\
\hline 78 & 0.03342 & 0.09762 & $2.09 \mathrm{E}-05$ & 0.03340 & 0.03344 \\
\hline 79 & 0.03346 & 0.09762 & $2.04 \mathrm{E}-05$ & 0.03344 & 03348 \\
\hline 80 & 0.03350 & 0.09762 & & 0.03348 & 352 \\
\hline 81 & 0.03354 & 0.09762 & 2.04E-05 & 0.03351 & 0.03356 \\
\hline 82 & 0.03357 & 0.09762 & $1.99 \mathrm{E}-05$ & 0.03355 & 0.03359 \\
\hline 83 & 0.03361 & 0.09762 & $1.95 \mathrm{E}-05$ & 0.03359 & 0.03363 \\
\hline 84 & 0.03365 & 0.09762 & $1.90 \mathrm{E}-05$ & 0.03363 & 0.03367 \\
\hline 85 & 0.03368 & 0.09762 & $1.86 \mathrm{E}-05$ & 0.03366 & 0.03370 \\
\hline 86 & 0.03372 & 0.09762 & $1.82 \mathrm{E}-05$ & 0.03370 & 0.03373 \\
\hline 87 & 0.03375 & 0.09762 & 1.77E-05 & 0.03373 & 0.03377 \\
\hline 88 & 0.03378 & 0.09762 & $1.73 \mathrm{E}-05$ & 0.03376 & 0.03380 \\
\hline 89 & 0.03381 & 0.09762 & $1.69 \mathrm{E}-05$ & 0.03380 & 0.03383 \\
\hline 90 & 0.03385 & 0.09762 & $1.65 \mathrm{E}-05$ & 0.03383 & 0.03386 \\
\hline 91 & 0.03388 & 0.09762 & $1.61 \mathrm{E}-05$ & 0.03386 & 0.03389 \\
\hline 92 & 0.03391 & 0.09763 & $1.58 \mathrm{E}-05$ & 0.03389 & 0.03392 \\
\hline 93 & 0.03393 & 0.09763 & $1.54 \mathrm{E}-05$ & 0.03392 & 0.03395 \\
\hline 94 & 0.03396 & 0.09763 & $1.50 \mathrm{E}-05$ & 0.03395 & 0.03398 \\
\hline 95 & 0.03399 & 0.09763 & $1.47 \mathrm{E}-05$ & 0.03398 & 0.03401 \\
\hline 96 & 0.03402 & 0.09763 & $1.44 \mathrm{E}-05$ & 0.03400 & 0.03403 \\
\hline
\end{tabular}




\begin{tabular}{|c|c|c|c|c|c|}
\hline $\mathrm{i}$ & $w(i)$ & $f(w(i))$ & $d(i)$ & $w(i)-d(i)$ & $w(i)+d(i)$ \\
\hline 97 & .03405 & 0.09763 & $1.41 \mathrm{E}-05$ & 0.03403 & 0.03406 \\
\hline 98 & 0.03407 & 0.09763 & 1.37E-05 & 0.03406 & 0.03408 \\
\hline 99 & 0.03410 & 0.09763 & $1.34 \mathrm{E}-05$ & 0.03408 & 0.03411 \\
\hline 100 & 0.03412 & 0.09763 & $1.31 \mathrm{E}-05$ & 0.03411 & 0.03413 \\
\hline 101 & 0.03415 & 0.09763 & $1.28 \mathrm{E}-05$ & 0.03413 & 0.03416 \\
\hline 102 & 0.03417 & 0.09763 & $1.26 \mathrm{E}-05$ & 0.03416 & 0.03418 \\
\hline 103 & 0.03419 & 0.09763 & $1.23 \mathrm{E}-05$ & 0.03418 & 0.03420 \\
\hline 104 & 0.03422 & 0.09763 & $1.20 \mathrm{E}-05$ & 0.03420 & 0.03423 \\
\hline 105 & 0.03424 & 0.09763 & $1.18 \mathrm{E}-05$ & 0.03423 & 0.03425 \\
\hline 106 & 0.03426 & 0.09763 & $1.15 \mathrm{E}-05$ & 0.03425 & 0.03427 \\
\hline 107 & 0.03428 & 0.09763 & $1.13 \mathrm{E}-05$ & 0.03427 & 0.03429 \\
\hline 108 & 0.03430 & 0.09763 & $1.10 \mathrm{E}-05$ & 0.03429 & 0.03431 \\
\hline 109 & 0.03432 & 0.09763 & $1.08 \mathrm{E}-05$ & 0.03431 & 0.03433 \\
\hline 110 & 0.03434 & 0.09763 & -05 & 433 & \\
\hline 111 & 0.03436 & 0.09763 & $1.03 \mathrm{E}-05$ & 0.03435 & 0.03437 \\
\hline 112 & 0.03438 & 0.09763 & 1.01E-05 & 0.03437 & 0.03439 \\
\hline 113 & & & & & \\
\hline 114 & 0.03442 & 0.09763 & $9.65 \mathrm{E}-06$ & 0.03441 & 0.03443 \\
\hline 115 & 0.03444 & 0.09763 & $9.45 \mathrm{E}-06$ & 443 & 444 \\
\hline 116 & & & & & \\
\hline 117 & 0.03447 & 0.09763 & $9.05 \mathrm{E}-06$ & 0.03446 & 0.03448 \\
\hline 118 & 0.03449 & 0.09763 & 8.86E-06 & 448 & 0.03450 \\
\hline 119 & 0.0 & 0.0 & -06 & 449 & 451 \\
\hline 120 & 0.03452 & 0.09763 & 8.50E-06 & 0.03451 & 0.03453 \\
\hline 121 & 0.03453 & 0.09763 & 8.34E-06 & 0.03453 & 0.03454 \\
\hline 122 & 0.0 & 63 & $=-06$ & 454 & 0.0 \\
\hline 123 & 0.03457 & 0.09763 & $8.00 \mathrm{E}-06$ & 0.03456 & 0.03457 \\
\hline 124 & 0.03458 & 0.09763 & $7.85 \mathrm{E}-06$ & 0.03457 & 0.03459 \\
\hline 125 & 0.03459 & 0.09763 & $E-06$ & 0.03459 & 0. \\
\hline 126 & 0.03461 & 0.09763 & 7.53E-06 & 0.03460 & 0.03462 \\
\hline 127 & 0.03462 & 763 & 7.37E-06 & 0.03462 & 0.03463 \\
\hline 128 & 0.03464 & 0.09763 & $=-06$ & 463 & 03464 \\
\hline 129 & 0.03465 & 0.09763 & 7.10E-06 & 0.03464 & 0.03466 \\
\hline 130 & 0.03466 & 0.09763 & $6.96 \mathrm{E}-06$ & 0.03466 & 0.03467 \\
\hline 131 & 0.03468 & 0.09763 & $6.81 \mathrm{E}-06$ & 0.03467 & 0.03468 \\
\hline 132 & 0.03469 & 0.09763 & 6.69E-06 & 0.03468 & 0.03470 \\
\hline 133 & 0.03470 & 0.09763 & $6.56 \mathrm{E}-06$ & 0.03469 & 0.03471 \\
\hline 134 & 0.03471 & 0.09763 & $6.42 \mathrm{E}-06$ & 0.03471 & 0.03472 \\
\hline 135 & 0.03472 & 0.09763 & $6.29 E-06$ & 0.03472 & 0.03473 \\
\hline 136 & 0.03474 & 0.09763 & $6.16 \mathrm{E}-06$ & 0.03473 & 0.03474 \\
\hline 137 & 0.03475 & 0.09763 & $6.03 \mathrm{E}-06$ & 0.03474 & 0.03475 \\
\hline 138 & 0.03476 & 0.09763 & $5.90 \mathrm{E}-06$ & 0.03475 & 0.03476 \\
\hline 139 & 0.03477 & 0.09763 & 5.77E-06 & 0.03476 & 0.03478 \\
\hline 140 & 0.03478 & 0.09763 & $5.65 \mathrm{E}-06$ & 0.03477 & 0.03479 \\
\hline 141 & 0.03479 & 0.09763 & $5.53 \mathrm{E}-06$ & 0.03479 & 0.03480 \\
\hline 142 & 0.03480 & 0.09763 & $5.42 \mathrm{E}-06$ & 0.03480 & 0.03481 \\
\hline 143 & 0.03481 & 0.09763 & 5.31E-06 & 0.03481 & 0.03482 \\
\hline 144 & 0.03482 & 0.09763 & $5.20 \mathrm{E}-06$ & 0.03482 & 0.03483 \\
\hline
\end{tabular}




\begin{tabular}{|c|c|c|c|c|c|}
\hline i & $w(i)$ & $f(w(i))$ & $d(i)$ & $w(i)-d(i)$ & $w(i)+d(i)$ \\
\hline 145 & 03483 & .09763 & 09E-06 & 0.03483 & 0.03484 \\
\hline 146 & 0.03484 & 0.09763 & 4.99E-06 & 3484 & 3485 \\
\hline 147 & 0.03485 & 0.09763 & $4.88 \mathrm{E}-06$ & 0.03484 & 0.03485 \\
\hline 148 & 0.03486 & 0.09763 & 4.78E-06 & 0.03485 & 0.03486 \\
\hline 149 & 0.03487 & 0.09763 & 4.68E-06 & 0.03486 & 0.03487 \\
\hline 150 & 0.03488 & 0.09763 & $4.58 \mathrm{E}-06$ & 0.03487 & 0.03488 \\
\hline 151 & 0.03488 & 0.09763 & $4.48 \mathrm{E}-06$ & 0.03488 & 0.03489 \\
\hline 152 & 0.03489 & 0.09763 & 4.39E-06 & 0.03489 & 490 \\
\hline 153 & 0.03490 & 0.09763 & 4.30E-06 & 0.03490 & 490 \\
\hline 154 & 0.03491 & 0.09763 & 4.21E-06 & 0.03490 & 0.03491 \\
\hline 155 & 0.03492 & 0.09763 & 4.12E-06 & 491 & \\
\hline 156 & 0.03492 & 763 & 06 & 492 & 493 \\
\hline 157 & 0.03493 & 0.09763 & 3.95E-06 & 0.03493 & 0.03494 \\
\hline 158 & 0.03494 & 0.09763 & 3.87E-06 & 493 & 194 \\
\hline 159 & 0.03495 & 0.09763 & 3.80E-06 & 0.03494 & 0.03495 \\
\hline 160 & 0.03495 & 0.09763 & 3.73E-06 & 0.03495 & 0.03496 \\
\hline 161 & 96 & 0.09763 & 3.65E-06 & 96 & 196 \\
\hline 162 & 0.03497 & 0.09763 & 3.60E-06 & 496 & 0.0 \\
\hline 163 & 0.03497 & 0.09763 & $4.50 \mathrm{E}-06$ & 0.03497 & 0.03498 \\
\hline 164 & 0.03498 & 0.09763 & $4.42 \mathrm{E}-06$ & 3498 & 499 \\
\hline 165 & 0.03499 & 0.09763 & 4.49E-06 & 0.03499 & 0.03499 \\
\hline 166 & 0.03500 & 0.09763 & 4.96E-06 & 0.03499 & 0.03500 \\
\hline 167 & 01 & 0.09763 & $E-06$ & 500 & 3501 \\
\hline 168 & 0.03502 & 0.09763 & $4.78 \mathrm{E}-06$ & 0.03501 & 0.03502 \\
\hline 169 & 0.03503 & 0.09763 & 4.69E-06 & 0.03502 & 0.03503 \\
\hline 170 & 03 & .09763 & -06 & 503 & 504 \\
\hline 171 & 0.03504 & 0.09763 & 4.5 & 504 & 505 \\
\hline 172 & 0.03505 & 0.09763 & $4.44 \mathrm{E}-06$ & 0.03505 & 0.03506 \\
\hline 173 & 0.03506 & 9763 & 4.36E-06 & 05 & 506 \\
\hline 174 & 0.03507 & 0.09763 & $4.28 \mathrm{E}-06$ & .03506 & 0.03507 \\
\hline 175 & 0.03507 & 0.09763 & $4.21 \mathrm{E}-06$ & 0.03507 & 0.03508 \\
\hline 176 & 0.03508 & 0.09763 & 4.13E-06 & 0.03508 & 0.03509 \\
\hline 177 & 0.03509 & 0.09763 & 4.06E-06 & 0.03509 & 0.03509 \\
\hline 178 & 0.03510 & 0.09763 & 3.99E-06 & 0.03509 & 0.03510 \\
\hline 179 & 0.03511 & 0.09763 & $3.92 \mathrm{E}-06$ & 0.03510 & 0.03511 \\
\hline 180 & 0.03511 & 0.09763 & 3.85E-06 & 0.03511 & 0.03512 \\
\hline 181 & 0.03512 & 0.09763 & $3.78 \mathrm{E}-06$ & 0.03512 & 0.03512 \\
\hline 182 & 0.03513 & 0.09763 & 3.71E-06 & 0.03512 & 0.03513 \\
\hline 183 & 0.03513 & 0.09763 & 3.65E-06 & 0.03513 & 0.03514 \\
\hline 184 & 0.03514 & 0.09763 & $3.58 \mathrm{E}-06$ & 0.03514 & 0.03514 \\
\hline 185 & 0.03515 & 0.09763 & 3.52E-06 & 0.03514 & 0.03515 \\
\hline 186 & 0.03515 & 0.09763 & $3.46 \mathrm{E}-06$ & 0.03515 & 0.03516 \\
\hline 187 & 0.03516 & 0.09763 & 3.39E-06 & 0.03516 & 0.03516 \\
\hline 188 & 0.03517 & 0.09763 & 3.33E-06 & 0.03516 & 0.03517 \\
\hline 189 & 0.03517 & 0.09763 & $3.28 \mathrm{E}-06$ & 0.03517 & 0.03518 \\
\hline 190 & 0.03518 & 0.09763 & $3.22 \mathrm{E}-06$ & 0.03517 & 0.03518 \\
\hline 191 & 0.03518 & 0.09763 & 3.16E-06 & 0.03518 & 0.03519 \\
\hline 192 & 0.03519 & 0.09763 & $3.11 \mathrm{E}-06$ & 0.03519 & 0.03519 \\
\hline
\end{tabular}




\begin{tabular}{|c|c|c|c|c|c|}
\hline i & $w(i)$ & $f(w(i))$ & $d(i)$ & $w(i)-d(i)$ & $w(i)+d(i)$ \\
\hline 193 & 03520 & .09763 & 3.05E-06 & 0.03519 & 0.03520 \\
\hline 194 & 0.03520 & 0.09763 & $3.00 \mathrm{E}-06$ & 0.03520 & 0.03520 \\
\hline 195 & 0.03521 & 0.09763 & $2.95 \mathrm{E}-06$ & 0.03520 & 0.03521 \\
\hline 196 & 0.03521 & 0.09763 & 2.89E-06 & 0.03521 & 0.03522 \\
\hline 197 & 0.03522 & 0.09763 & $2.84 \mathrm{E}-06$ & 0.03521 & 0.03522 \\
\hline 198 & 0.03522 & 0.09763 & $2.79 \mathrm{E}-06$ & 0.03522 & 0.03523 \\
\hline 199 & 0.03523 & 0.09763 & $2.75 \mathrm{E}-06$ & 0.03523 & 0.03523 \\
\hline 200 & 0.03523 & 0.09763 & $2.71 \mathrm{E}-06$ & 0.03523 & 0.03524 \\
\hline 201 & 0.03524 & 0.09763 & 2.67E-06 & 0.03524 & 0.03524 \\
\hline 202 & 0.03524 & 0.09763 & $3.53 \mathrm{E}-06$ & 0.03524 & 0.03525 \\
\hline 203 & 0.03525 & 0.09763 & 8.88E-06 & 0.03524 & 526 \\
\hline 204 & 0.03527 & 0.09763 & 8.77E-06 & 0.03526 & 0.03527 \\
\hline 205 & 0.03528 & 0.09763 & $8.72 \mathrm{E}-06$ & 0.03527 & 0.03529 \\
\hline 206 & 0.03530 & 0.09763 & 8.61E-06 & 0.03529 & 0.03531 \\
\hline 207 & 0.03531 & 0.09763 & $8.51 \mathrm{E}-06$ & 0.03531 & 0.03532 \\
\hline 208 & 0.03533 & 0.09763 & $8.42 \mathrm{E}-06$ & 0.03532 & 0.03534 \\
\hline 209 & 0.03535 & 0.09763 & 8.33E-06 & 0.03534 & 0.03535 \\
\hline 210 & 0.03536 & 0.09763 & $8.24 \mathrm{E}-06$ & 0.03535 & 0.03537 \\
\hline 211 & 0.03538 & 0.09763 & 8.15E-06 & 0.03537 & 0.03538 \\
\hline 212 & 0.03 & 0.0 & 8.11E-06 & 3538 & 540 \\
\hline 213 & 0.03541 & 0.09763 & 8.01E-06 & 0.03540 & 0.03541 \\
\hline 214 & 0.03542 & 0.09763 & 7.92E-06 & 0.03541 & 0.03543 \\
\hline 215 & 0.03544 & 0.09763 & $7.82 \mathrm{E}-06$ & 0.03543 & 03544 \\
\hline 216 & 0.03545 & 0.09763 & 7.73E-06 & 0.03544 & 0.03546 \\
\hline 217 & 0.03546 & 0.09763 & 7.64E-06 & 0.03546 & 0.03547 \\
\hline 218 & 0.03548 & 0. & 7.5 & 47 & 549 \\
\hline 219 & 0.03549 & 0.09763 & $7.60 \mathrm{E}-06$ & 0.03549 & 0.03550 \\
\hline 220 & 0.03551 & 0.09763 & 7.51E-06 & 0.03550 & 0.03551 \\
\hline 221 & 0.03552 & 0.09763 & 7.43E-06 & 0.03551 & 3553 \\
\hline 222 & 0.03553 & 0.09763 & 7.34E-06 & 0.03553 & 0.03554 \\
\hline 223 & 0.03555 & 0.09763 & $7.26 \mathrm{E}-06$ & 0.03554 & 0.03556 \\
\hline 224 & 0.03556 & 0.09763 & $7.18 \mathrm{E}-06$ & 0.03555 & 0.03557 \\
\hline 225 & 0.03557 & 0.09763 & 7.11E-06 & 0.03557 & 0.03558 \\
\hline 226 & 0.03559 & 0.09763 & 7.03E-06 & 0.03558 & 0.03560 \\
\hline 227 & 0.03560 & 0.09763 & 6.95E-06 & 0.03559 & 0.03561 \\
\hline 228 & 0.03561 & 0.09763 & $6.88 \mathrm{E}-06$ & 0.03561 & 0.03562 \\
\hline 229 & 0.03563 & 0.09763 & $6.80 \mathrm{E}-06$ & 0.03562 & 0.03563 \\
\hline 230 & 0.03564 & 0.09763 & $6.73 \mathrm{E}-06$ & 0.03563 & 0.03565 \\
\hline 231 & 0.03565 & 0.09763 & 6.66E-06 & 0.03564 & 0.03566 \\
\hline 232 & 0.03566 & 0.09763 & $6.59 \mathrm{E}-06$ & 0.03566 & 0.03567 \\
\hline 233 & 0.03568 & 0.09763 & $6.54 \mathrm{E}-06$ & 0.03567 & 0.03568 \\
\hline 234 & 0.03569 & 0.09763 & 6.47E-06 & 0.03568 & 0.03569 \\
\hline 235 & 0.03570 & 0.09763 & $6.40 \mathrm{E}-06$ & 0.03569 & 0.03571 \\
\hline 236 & 0.03571 & 0.09763 & $6.34 \mathrm{E}-06$ & 0.03571 & 0.03572 \\
\hline 237 & 0.03572 & 0.09763 & $6.29 \mathrm{E}-06$ & 0.03572 & 0.03573 \\
\hline 238 & 0.03574 & 0.09763 & $6.22 \mathrm{E}-06$ & 0.03573 & 0.03574 \\
\hline 239 & 0.03575 & 0.09763 & $6.15 \mathrm{E}-06$ & 0.03574 & 0.03575 \\
\hline 240 & 0.03576 & 0.09763 & $6.08 \mathrm{E}-06$ & 0.03575 & 0.03576 \\
\hline
\end{tabular}




\begin{tabular}{|c|c|c|c|c|c|}
\hline i & $w(i)$ & $f(w(i))$ & $d(i)$ & $w(i)-d(i)$ & $w(i)+d(i)$ \\
\hline 241 & 03577 & .09763 & $6.02 \mathrm{E}-06$ & 0.03576 & 0.03578 \\
\hline 242 & 0.03578 & 0.09763 & 5.96E-06 & 0.03577 & 0.03579 \\
\hline 243 & 0.03579 & 0.09763 & 5.89E-06 & 0.03579 & 0.03580 \\
\hline 244 & 0.03580 & 0.09763 & 5.83E-06 & 0.03580 & 0.03581 \\
\hline 245 & 0.03581 & 0.09763 & $5.78 \mathrm{E}-06$ & 0.03581 & 0.03582 \\
\hline 246 & 0.03582 & 0.09763 & $5.72 \mathrm{E}-06$ & 0.03582 & 0.03583 \\
\hline 247 & 0.03583 & 0.09763 & 5.67E-06 & 0.03583 & 0.03584 \\
\hline 248 & 0.03585 & 0.09763 & 5.61E-06 & 0.03584 & 0.03585 \\
\hline 249 & 0.03586 & 0.09763 & 5.55E-06 & 0.03585 & 0.03586 \\
\hline 250 & 0.03587 & 0.09763 & $5.50 \mathrm{E}-06$ & 0.03586 & 0.03587 \\
\hline 251 & 0.03588 & 0.09763 & 5.44E-06 & 0.03587 & 588 \\
\hline 252 & 0.03589 & 0.09763 & 5.39E-06 & 0.03588 & 0.03589 \\
\hline 253 & 0.03590 & 0.09763 & 5.50E-06 & 0.03589 & 0.03590 \\
\hline 254 & 0.03591 & 0.09763 & $5.48 \mathrm{E}-06$ & 0.03590 & 0.03591 \\
\hline 255 & 0.03592 & 0.09763 & $5.43 \mathrm{E}-06$ & 0.03591 & 0.03592 \\
\hline 256 & 0.03593 & 0.09763 & $5.41 \mathrm{E}-06$ & 0.03592 & 0.03593 \\
\hline 257 & 0.03594 & 0.09763 & 5.37E-06 & 0.03593 & 594 \\
\hline 258 & 0.03595 & 0.09763 & 5.35E-06 & 0.03594 & 0.03595 \\
\hline 259 & 0.03596 & 0.09763 & 5.30E-06 & 0.03595 & 0.03596 \\
\hline 260 & 0.03 & 0.0 & 5.27E-06 & 3596 & 597 \\
\hline 261 & 0.03598 & 0.09763 & $5.22 \mathrm{E}-06$ & 0.03597 & 0.03598 \\
\hline 262 & 0.03599 & 0.09763 & $5.20 \mathrm{E}-06$ & 0.03598 & 0.03599 \\
\hline 263 & 0.03600 & & $5.15 \mathrm{~B}$ & 599 & \\
\hline 264 & 0.03600 & 0.09763 & 5.14E-06 & 0.03600 & 0.03601 \\
\hline 265 & 0.03601 & 0.09763 & 5.10E-06 & 0.03601 & 0.03602 \\
\hline 266 & 0.03602 & 0. & & 502 & 503 \\
\hline 267 & 0.03603 & 0.09763 & $5.02 \mathrm{E}-06$ & 0.03603 & 0.03604 \\
\hline 268 & 0.03604 & 0.09763 & $4.98 \mathrm{E}-06$ & 0.03604 & 0.03605 \\
\hline 269 & 0.03605 & 0.09763 & 4.94E-06 & 0.03605 & 0.03606 \\
\hline 270 & 0.03606 & 0.09763 & 4.90E-06 & 0.03606 & 0.03607 \\
\hline 271 & 0.03607 & 0.09763 & $4.86 \mathrm{E}-06$ & 0.03606 & 0.03607 \\
\hline 272 & 0.03608 & 0.09763 & $4.82 \mathrm{E}-06$ & 0.03607 & 0.03608 \\
\hline 273 & 0.03609 & 0.09763 & $4.78 \mathrm{E}-06$ & 0.03608 & 0.03609 \\
\hline 274 & 0.03610 & 0.09763 & 4.74E-06 & 0.03609 & 0.03610 \\
\hline 275 & 0.03611 & 0.09763 & 4.71E-06 & 0.03610 & 0.03611 \\
\hline 276 & 0.03611 & 0.09763 & 4.67E-06 & 0.03611 & 0.03612 \\
\hline 277 & 0.03612 & 0.09763 & $4.62 \mathrm{E}-06$ & 0.03612 & 0.03613 \\
\hline 278 & 0.03613 & 0.09763 & $4.58 \mathrm{E}-06$ & 0.03613 & 0.03614 \\
\hline 279 & 0.03614 & 0.09763 & 4.54E-06 & 0.03613 & 0.03614 \\
\hline 280 & 0.03615 & 0.09763 & $4.50 \mathrm{E}-06$ & 0.03614 & 0.03615 \\
\hline 281 & 0.03616 & 0.09763 & $4.46 \mathrm{E}-06$ & 0.03615 & 0.03616 \\
\hline 282 & 0.03616 & 0.09763 & $4.41 \mathrm{E}-06$ & 0.03616 & 0.03617 \\
\hline 283 & 0.03617 & 0.09763 & 4.37E-06 & 0.03617 & 0.03618 \\
\hline 284 & 0.03618 & 0.09763 & 4.37E-06 & 0.03618 & 0.03619 \\
\hline 285 & 0.03619 & 0.09763 & 4.33E-06 & 0.03618 & 0.03619 \\
\hline 286 & 0.03620 & 0.09763 & 4.29E-06 & 0.03619 & 0.03620 \\
\hline 287 & 0.03620 & 0.09763 & $4.25 \mathrm{E}-06$ & 0.03620 & 0.03621 \\
\hline 288 & 0.03621 & 0.09763 & 4.23E-06 & 0.03621 & 0.03622 \\
\hline
\end{tabular}




\begin{tabular}{|c|c|c|c|c|c|}
\hline i & $w(i)$ & $f(w(i))$ & $d(i)$ & $w(i)-d(i)$ & $w(i)+d(i)$ \\
\hline 289 & 03622 & .09763 & 4.19E-06 & 0.03622 & 0.03622 \\
\hline 290 & 0.03623 & 0.09763 & 4.17E-06 & 0.03622 & 0.03623 \\
\hline 291 & 0.03624 & 0.09763 & 4.14E-06 & 0.03623 & 0.03624 \\
\hline 292 & 0.03624 & 0.09763 & 4.10E-06 & 0.03624 & 0.03625 \\
\hline 293 & 0.03625 & 0.09763 & 4.07E-06 & 0.03625 & 0.03626 \\
\hline 294 & 0.03626 & 0.09763 & 4.03E-06 & 0.03625 & 0.03626 \\
\hline 295 & 0.03627 & 0.09763 & 4.01E-06 & 0.03626 & 0.03627 \\
\hline 296 & 0.03627 & 0.09763 & 3.99E-06 & 0.03627 & 0.03628 \\
\hline 297 & 0.03628 & 0.09763 & 3.97E-06 & 0.03628 & 0.03628 \\
\hline 298 & 0.03629 & 0.09763 & $3.93 \mathrm{E}-06$ & 0.03628 & 0.03629 \\
\hline 299 & 0.03630 & 0.09763 & 3.90E-06 & 0.03629 & 0.03630 \\
\hline 300 & 0.03630 & 0.09763 & 3.87E-06 & 0.03630 & 0.03631 \\
\hline 301 & 0.03631 & 0.09763 & 3.84E-06 & 0.03631 & 0.03631 \\
\hline 302 & 0.03632 & 0.09763 & 3.81E-06 & 0.03631 & 0.03632 \\
\hline 303 & 0.03632 & 0.09763 & $3.78 \mathrm{E}-06$ & 0.03632 & 0.03633 \\
\hline 304 & 0.03633 & 0.09763 & 3.75E-06 & 0.03633 & 0.03633 \\
\hline 305 & 0.03634 & 0.09763 & $3.72 \mathrm{E}-06$ & 0.03633 & 0.03634 \\
\hline 306 & 0.03634 & 0.09763 & 3.69E-06 & 0.03634 & 0.03635 \\
\hline 307 & 0.03635 & 0.09763 & 3.67E-06 & 0.03635 & 0.03636 \\
\hline 308 & 0.03636 & 0.09763 & 3.64E-06 & 3635 & 3636 \\
\hline 309 & 0.03637 & 0.09763 & 3.61E-06 & 0.03636 & 0.03637 \\
\hline 310 & 0.03637 & 0.09763 & $3.58 \mathrm{E}-06$ & 0.03637 & 0.03638 \\
\hline 311 & 0.03638 & 0.09763 & $3.55 \mathrm{E}-06$ & 0.03637 & 0.03638 \\
\hline 312 & 0.03639 & 0.09763 & $3.52 \mathrm{E}-06$ & 0.03638 & 0.03639 \\
\hline 313 & 0.03639 & 0.09763 & 3.50E-06 & 0.03639 & 0.03640 \\
\hline 314 & 0.03640 & 0.09763 & 3.47E-06 & 0.03639 & 0.03640 \\
\hline 315 & 0.03640 & 0.09763 & $3.45 \mathrm{E}-06$ & 0.03640 & 0.03641 \\
\hline 316 & 0.03641 & 0.09763 & $3.41 \mathrm{E}-06$ & 0.03641 & 0.03641 \\
\hline 317 & 0.03642 & 0.09763 & $3.38 \mathrm{E}-06$ & 0.03641 & 0.03642 \\
\hline 318 & 0.03642 & 0.09763 & 3.35E-06 & 0.03642 & 0.03643 \\
\hline 319 & 0.03643 & 0.09763 & 3.33E-06 & 0.03643 & 0.03643 \\
\hline 320 & 0.03644 & 0.09763 & 3.30E-06 & 0.03643 & 0.03644 \\
\hline 321 & 0.03644 & 0.09763 & 3.27E-06 & 0.03644 & 0.03645 \\
\hline 322 & 0.03645 & 0.09763 & $3.25 \mathrm{E}-06$ & 0.03644 & 0.03645 \\
\hline 323 & 0.03645 & 0.09763 & $3.22 \mathrm{E}-06$ & 0.03645 & 0.03646 \\
\hline 324 & 0.03646 & 0.09763 & 3.19E-06 & 0.03646 & 0.03646 \\
\hline 325 & 0.03647 & 0.09763 & 3.19E-06 & 0.03646 & 0.03647 \\
\hline 326 & 0.03647 & 0.09763 & 3.16E-06 & 0.03647 & 0.03647 \\
\hline 327 & 0.03648 & 0.09763 & 3.13E-06 & 0.03647 & 0.03648 \\
\hline 328 & 0.03648 & 0.09763 & 3.13E-06 & 0.03648 & 0.03649 \\
\hline 329 & 0.03649 & 0.09763 & 3.11E-06 & 0.03649 & 0.03649 \\
\hline 330 & 0.03649 & 0.09763 & $3.08 \mathrm{E}-06$ & 0.03649 & 0.03650 \\
\hline 331 & 0.03650 & 0.09763 & 3.66E-06 & 0.03650 & 0.03650 \\
\hline 332 & 0.03651 & 0.09763 & 3.65E-06 & 0.03650 & 0.03651 \\
\hline 333 & 0.03651 & 0.09763 & $3.63 \mathrm{E}-06$ & 0.03651 & 0.03652 \\
\hline 334 & 0.03652 & 0.09763 & $3.62 \mathrm{E}-06$ & 0.03652 & 0.03652 \\
\hline 335 & 0.03653 & 0.09763 & 3.61E-06 & 0.03652 & 0.03653 \\
\hline 336 & 0.03653 & 0.09763 & $3.60 \mathrm{E}-06$ & 0.03653 & 0.03654 \\
\hline
\end{tabular}




\begin{tabular}{|c|c|c|c|c|c|}
\hline i & $w(i)$ & $f(w(i))$ & $d(i)$ & $w(i)-d(i)$ & $w(i)+d(i)$ \\
\hline 337 & 0.03654 & 0.09763 & $3.58 \mathrm{E}-06$ & 0.03654 & 0.03654 \\
\hline 338 & 0.03655 & 0.09763 & $3.56 \mathrm{E}-06$ & 0.03654 & 0.03655 \\
\hline 339 & 0.03655 & 0.09763 & $3.55 \mathrm{E}-06$ & 0.03655 & 0.03656 \\
\hline 340 & 0.03656 & 0.09763 & $3.53 \mathrm{E}-06$ & 0.03656 & 0.03656 \\
\hline 341 & 0.03657 & 0.09763 & $3.51 \mathrm{E}-06$ & 0.03656 & 0.03657 \\
\hline 342 & 0.03657 & 0.09763 & $3.49 E-06$ & 0.03657 & 0.03658 \\
\hline 343 & 0.03658 & 0.09763 & 3.47E-06 & 0.03658 & 0.03658 \\
\hline 344 & 0.03659 & 0.09763 & $3.46 \mathrm{E}-06$ & 0.03658 & 0.03659 \\
\hline 345 & 0.03659 & 0.09763 & $3.46 \mathrm{E}-06$ & 0.03659 & 0.03660 \\
\hline 346 & 0.03660 & 0.09763 & $3.44 \mathrm{E}-06$ & 0.03660 & 0.03660 \\
\hline 347 & 0.03661 & 0.09763 & $3.43 E-06$ & 0.03660 & 0.03661 \\
\hline 348 & 0.03661 & 0.09763 & $3.41 \mathrm{E}-06$ & 0.03661 & 0.03662 \\
\hline 349 & 0.03662 & 0.09763 & 3.39E-06 & 0.03661 & 0.03662 \\
\hline 350 & 0.03662 & 0.09763 & 3.37E-06 & 0.03662 & 0.03663 \\
\hline 351 & 0.03663 & 0.09763 & $3.35 \mathrm{E}-06$ & 0.03663 & 0.03663 \\
\hline 352 & 0.03664 & 0.09763 & 3.34E-06 & 0.03663 & 0.03664 \\
\hline 353 & 0.03664 & 0.09763 & 3.32E-06 & 0.03664 & 0.03665 \\
\hline 354 & 0.03665 & 0.09763 & 3.30E-06 & 0.03665 & 0.03665 \\
\hline 355 & 0.03666 & 0.09763 & $3.28 \mathrm{E}-06$ & 0.03665 & 0.03666 \\
\hline 356 & 0.03666 & 0.0 & 06 & 03666 & 03666 \\
\hline 357 & 0.03667 & 0.09763 & $3.24 \mathrm{E}-06$ & 0.03666 & 0.03667 \\
\hline 358 & 0.03667 & 0.09763 & $3.22 \mathrm{E}-06$ & 0.03667 & 0.03668 \\
\hline 359 & 0.03668 & & & 03668 & 3668 \\
\hline 360 & 0.03669 & 0.09763 & 3.19E-06 & 0.03668 & 0.03669 \\
\hline 361 & 0.03669 & 0.09763 & 3.17E-06 & 0.03669 & 0.03669 \\
\hline 362 & 0.036 & 0. & 3 & 569 & 570 \\
\hline 363 & 0.03670 & 0.09763 & $3.14 \mathrm{E}-06$ & 0.03670 & 0.03671 \\
\hline 364 & 0.03671 & 0.09763 & $3.12 \mathrm{E}-06$ & 0.03671 & 0.03671 \\
\hline 365 & 0.03671 & 0.09763 & $3.10 \mathrm{E}-06$ & 0.03671 & 03672 \\
\hline 366 & 0.03672 & 0.09763 & $3.08 \mathrm{E}-06$ & 0.03672 & 0.03672 \\
\hline 367 & 0.03673 & 0.09763 & 3.07E-06 & 0.03672 & 0.03673 \\
\hline 368 & 0.03673 & 0.09763 & $3.13 \mathrm{E}-06$ & 0.03673 & 0.03673 \\
\hline 369 & 0.03674 & 0.09763 & $3.12 \mathrm{E}-06$ & 0.03673 & 0.03674 \\
\hline 370 & 0.03674 & 0.09763 & 3.10E-06 & 0.03674 & 0.03675 \\
\hline 371 & 0.03675 & 0.09763 & $3.08 \mathrm{E}-06$ & 0.03675 & 0.03675 \\
\hline 372 & 0.03675 & 0.09763 & 3.07E-06 & 0.03675 & 0.03676 \\
\hline 373 & 0.03676 & 0.09763 & $3.05 \mathrm{E}-06$ & 0.03676 & 0.03676 \\
\hline 374 & 0.03677 & 0.09763 & $3.03 E-06$ & 0.03676 & 0.03677 \\
\hline 375 & 0.03677 & 0.09763 & $3.02 \mathrm{E}-06$ & 0.03677 & 0.03677 \\
\hline 376 & 0.03678 & 0.09763 & $3.01 \mathrm{E}-06$ & 0.03677 & 0.03678 \\
\hline 377 & 0.03678 & 0.09763 & $2.99 \mathrm{E}-06$ & 0.03678 & 0.03679 \\
\hline 378 & 0.03679 & 0.09763 & $2.97 \mathrm{E}-06$ & 0.03679 & 0.03679 \\
\hline 379 & 0.03679 & 0.09763 & $2.96 \mathrm{E}-06$ & 0.03679 & 0.03680 \\
\hline 380 & 0.03680 & 0.09763 & $2.94 \mathrm{E}-06$ & 0.03680 & 0.03680 \\
\hline 381 & 0.03680 & 0.09763 & $2.93 \mathrm{E}-06$ & 0.03680 & 0.03681 \\
\hline 382 & 0.03681 & 0.09763 & $2.91 \mathrm{E}-06$ & 0.03681 & 0.03681 \\
\hline 383 & 0.03682 & 0.09763 & $2.91 \mathrm{E}-06$ & 0.03681 & 0.03682 \\
\hline 384 & 0.03682 & 0.09763 & $2.90 \mathrm{E}-06$ & 0.03682 & 0.03682 \\
\hline
\end{tabular}




\begin{tabular}{|c|c|c|c|c|c|}
\hline i & $w(i)$ & $f(w(i))$ & $d(i)$ & $w(i)-d(i)$ & $w(i)+d(i)$ \\
\hline 385 & 03683 & .09763 & $2.89 \mathrm{E}-06$ & 0.03682 & 0.03683 \\
\hline 386 & 0.03683 & 0.09763 & $2.88 \mathrm{E}-06$ & 0.03683 & 0.03683 \\
\hline 387 & 0.03684 & 0.09763 & 2.87E-06 & 0.03683 & 0.03684 \\
\hline 388 & 0.03684 & 0.09763 & $2.85 \mathrm{E}-06$ & 0.03684 & 0.03685 \\
\hline 389 & 0.03685 & 0.09763 & $2.84 \mathrm{E}-06$ & 0.03684 & 0.03685 \\
\hline 390 & 0.03685 & 0.09763 & $2.85 \mathrm{E}-06$ & 0.03685 & 0.03686 \\
\hline 391 & 0.03686 & 0.09763 & $2.83 \mathrm{E}-06$ & 0.03686 & 0.03686 \\
\hline 392 & 0.03686 & 0.09763 & $2.82 \mathrm{E}-06$ & 0.03686 & 0.03687 \\
\hline 393 & 0.03687 & 0.09763 & 2.80E-06 & 0.03687 & 0.03687 \\
\hline 394 & 0.03687 & 0.09763 & $2.79 \mathrm{E}-06$ & 0.03687 & 0.03688 \\
\hline 395 & 0.03688 & 0.09763 & $2.78 \mathrm{E}-06$ & 0.03688 & 0.03688 \\
\hline 396 & 0.03688 & 0.09763 & $2.80 \mathrm{E}-06$ & 3688 & 0.03689 \\
\hline 397 & 0.03689 & 0.09763 & $2.78 \mathrm{E}-06$ & 0.03689 & 0.03689 \\
\hline 398 & 0.03689 & 0.09763 & 2.77E-06 & 0.03689 & 0.03690 \\
\hline 399 & 0.03690 & 0.09763 & 2.76E-06 & 0.03690 & 0.03690 \\
\hline 400 & 0.03690 & 0.09763 & $2.74 \mathrm{E}-06$ & 0.03690 & 0.03691 \\
\hline 401 & 0.03691 & 0.09763 & $2.73 \mathrm{E}-06$ & 0.03691 & 0.03691 \\
\hline 402 & 0.03691 & 0.09763 & $2.72 \mathrm{E}-06$ & 0.03691 & 0.03692 \\
\hline 403 & 0.03692 & 0.09763 & 2.71E-06 & 0.03692 & 0.03692 \\
\hline 404 & 0.03692 & 0.09763 & -06 & 3692 & 3693 \\
\hline 405 & 0.03693 & 0.09763 & 2.69E-06 & 0.03693 & 0.03693 \\
\hline 406 & 0.03693 & 0.09763 & 2.69E-06 & 0.03693 & 0.03694 \\
\hline 407 & 0.03694 & 0.09763 & $2.68 \mathrm{E}-06$ & 0.03694 & 0.03694 \\
\hline 408 & 0.03694 & 0.09763 & $2.66 \mathrm{E}-06$ & 0.03694 & 0.03695 \\
\hline 409 & 0.03695 & 0.09763 & $2.65 \mathrm{E}-06$ & 0.03695 & 0.03695 \\
\hline 410 & 0.03695 & 0.09763 & $2.64 \mathrm{E}-06$ & 0.03695 & 3696 \\
\hline 411 & 0.03696 & 0.09763 & $2.63 \mathrm{E}-06$ & 0.03696 & 0.03696 \\
\hline 412 & 0.03696 & 0.09763 & $2.61 \mathrm{E}-06$ & 0.03696 & 0.03697 \\
\hline 413 & 0.03697 & 0.09763 & 2.60E-06 & 0.03697 & 0.03697 \\
\hline 414 & 0.03697 & 0.09763 & $2.59 \mathrm{E}-06$ & 0.03697 & 0.03698 \\
\hline 415 & 0.03698 & 0.09763 & $2.58 \mathrm{E}-06$ & 0.03698 & 0.03698 \\
\hline 416 & 0.03698 & 0.09763 & 2.57E-06 & 0.03698 & 0.03699 \\
\hline 417 & 0.03699 & 0.09763 & $2.55 \mathrm{E}-06$ & 0.03699 & 0.03699 \\
\hline 418 & 0.03699 & 0.09763 & $2.54 \mathrm{E}-06$ & 0.03699 & 0.03700 \\
\hline 419 & 0.03700 & 0.09763 & $2.53 \mathrm{E}-06$ & 0.03700 & 0.03700 \\
\hline 420 & 0.03700 & 0.09763 & $2.52 \mathrm{E}-06$ & 0.03700 & 0.03700 \\
\hline 421 & 0.03701 & 0.09763 & $2.51 \mathrm{E}-06$ & 0.03700 & 0.03701 \\
\hline 422 & 0.03701 & 0.09763 & $2.50 \mathrm{E}-06$ & 0.03701 & 0.03701 \\
\hline 423 & 0.03702 & 0.09763 & $2.49 \mathrm{E}-06$ & 0.03701 & 0.03702 \\
\hline 424 & 0.03702 & 0.09763 & 2.47E-06 & 0.03702 & 0.03702 \\
\hline 425 & 0.03703 & 0.09763 & $2.46 \mathrm{E}-06$ & 0.03702 & 0.03703 \\
\hline 426 & 0.03703 & 0.09763 & $2.45 \mathrm{E}-06$ & 0.03703 & 0.03703 \\
\hline 427 & 0.03703 & 0.09763 & $2.44 \mathrm{E}-06$ & 0.03703 & 0.03704 \\
\hline 428 & 0.03704 & 0.09763 & $2.43 \mathrm{E}-06$ & 0.03704 & 0.03704 \\
\hline 429 & 0.03704 & 0.09763 & $2.42 \mathrm{E}-06$ & 0.03704 & 0.03705 \\
\hline 430 & 0.03705 & 0.09763 & $2.41 \mathrm{E}-06$ & 0.03705 & 0.03705 \\
\hline 431 & 0.03705 & 0.09763 & $2.40 \mathrm{E}-06$ & 0.03705 & 0.03705 \\
\hline 432 & 0.03706 & 0.09763 & $2.39 \mathrm{E}-06$ & 0.03705 & 0.03706 \\
\hline
\end{tabular}




\begin{tabular}{|c|c|c|c|c|c|}
\hline i & $w(i)$ & $f(w(i))$ & $d(i)$ & $w(i)-d(i)$ & $w(i)+d(i)$ \\
\hline 433 & 03706 & .09763 & $2.38 \mathrm{E}-06$ & 0.03706 & 0.03706 \\
\hline 434 & 0.03707 & 0.09763 & $2.45 \mathrm{E}-06$ & 0.03706 & 3707 \\
\hline 435 & 0.03707 & 0.09763 & $2.44 \mathrm{E}-06$ & 0.03707 & 0.03707 \\
\hline 436 & 0.03707 & 0.09763 & $2.43 \mathrm{E}-06$ & 0.03707 & 0.03708 \\
\hline 437 & 0.03708 & 0.09763 & $2.42 \mathrm{E}-06$ & 0.03708 & 0.03708 \\
\hline 438 & 0.03708 & 0.09763 & $2.41 \mathrm{E}-06$ & 0.03708 & 0.03709 \\
\hline 439 & 0.03709 & 0.09763 & $2.41 \mathrm{E}-06$ & 0.03709 & 0.03709 \\
\hline 440 & 0.03709 & 0.09763 & $2.40 \mathrm{E}-06$ & 0.03709 & 0.03710 \\
\hline 441 & 0.03710 & 0.09763 & 2.39E-06 & 709 & 710 \\
\hline 442 & 0.03710 & 0.09763 & $2.40 \mathrm{E}-06$ & 0.03710 & 0.03710 \\
\hline 443 & 0.03711 & 0.09763 & 2.39E-06 & 710 & \\
\hline 444 & 11 & 763 & 06 & 11 & 11 \\
\hline 445 & 0.03711 & 0.09763 & 2.37E-06 & 0.03711 & 0.03712 \\
\hline 446 & 0.03712 & 0.09763 & $2.36 \mathrm{E}-06$ & 712 & 712 \\
\hline 447 & 0.03712 & 0.09763 & 2.3 & 12 & 13 \\
\hline 448 & 0.03713 & 0.09763 & $2.36 \mathrm{E}-06$ & 0.03713 & 0.03713 \\
\hline 449 & 713 & 0.09763 & $2.36 \mathrm{E}-06$ & 13 & 13 \\
\hline 450 & 0.03714 & 0.09763 & $2.35 \mathrm{E}-06$ & 713 & 0.0 \\
\hline 451 & 0.03714 & 0.09763 & $2.35 \mathrm{E}-06$ & 0.03714 & 0.03714 \\
\hline 452 & 0.03715 & 0.09763 & $2.42 \mathrm{E}-06$ & 714 & 715 \\
\hline 453 & 0.03715 & 0.09763 & $2.79 \mathrm{E}-06$ & 0.03715 & 0.0 \\
\hline 454 & 0.03716 & 0.09763 & $2.84 \mathrm{E}-06$ & 0.03715 & 0.03716 \\
\hline 455 & 716 & 0.09763 & $2.86 \mathrm{E}-06$ & 3716 & 716 \\
\hline 456 & 0.03717 & 0.09763 & $2.88 \mathrm{E}-06$ & 0.03716 & 0.03717 \\
\hline 457 & 0.03717 & 0.09763 & 2.90E-06 & 0.03717 & 0.03717 \\
\hline 458 & 18 & 0.09763 & 2.9 & 3717 & 3718 \\
\hline 459 & 0.03718 & 0.09763 & 2.9 & 718 & \\
\hline 460 & 0.03719 & 0.09763 & $2.91 \mathrm{E}-06$ & 0.03718 & 0.03719 \\
\hline 461 & 0.03719 & 0.09763 & 2.90E-06 & 719 & 0.03720 \\
\hline 462 & 0.03720 & 0.09763 & $2.90 \mathrm{E}-06$ & 719 & 0.03720 \\
\hline 463 & 0.03720 & 0.09763 & 2.89E-06 & 0.03720 & 0.03721 \\
\hline 464 & 0.03721 & 0.09763 & $2.89 \mathrm{E}-06$ & 0.03721 & 0.03721 \\
\hline 465 & 0.03721 & 0.09763 & $2.88 \mathrm{E}-06$ & 0.03721 & 0.03722 \\
\hline 466 & 0.03722 & 0.09763 & $2.88 \mathrm{E}-06$ & 0.03722 & 0.03722 \\
\hline 467 & 0.03722 & 0.09763 & 2.87E-06 & 0.03722 & 0.03723 \\
\hline 468 & 0.03723 & 0.09763 & 2.87E-06 & 0.03723 & 0.03723 \\
\hline 469 & 0.03724 & 0.09763 & $2.86 \mathrm{E}-06$ & 0.03723 & 0.03724 \\
\hline 470 & 0.03724 & 0.09763 & $2.86 \mathrm{E}-06$ & 0.03724 & 0.03724 \\
\hline 471 & 0.03725 & 0.09763 & $2.86 \mathrm{E}-06$ & 0.03724 & 0.03725 \\
\hline 472 & 0.03725 & 0.09763 & $2.85 \mathrm{E}-06$ & 0.03725 & 0.03725 \\
\hline 473 & 0.03726 & 0.09763 & $2.85 \mathrm{E}-06$ & 0.03725 & 0.03726 \\
\hline 474 & 0.03726 & 0.09763 & $2.84 \mathrm{E}-06$ & 0.03726 & 0.03726 \\
\hline 475 & 0.03727 & 0.09763 & $2.84 \mathrm{E}-06$ & 0.03726 & 0.03727 \\
\hline 476 & 0.03727 & 0.09763 & 2.87E-06 & 0.03727 & 0.03727 \\
\hline 477 & 0.03728 & 0.09763 & 2.87E-06 & 0.03727 & 0.03728 \\
\hline 478 & 0.03728 & 0.09763 & $2.86 \mathrm{E}-06$ & 0.03728 & 0.03729 \\
\hline 479 & 0.03729 & 0.09763 & $2.86 \mathrm{E}-06$ & 0.03729 & 0.03729 \\
\hline 480 & 0.03729 & 0.09763 & $2.85 \mathrm{E}-06$ & 0.03729 & 0.03730 \\
\hline
\end{tabular}




\begin{tabular}{|c|c|c|c|c|c|}
\hline i & $w(i)$ & $f(w(i))$ & $d(i)$ & $w(i)-d(i)$ & $w(i)+d(i)$ \\
\hline 481 & 0.03730 & .09763 & $2.85 \mathrm{E}-06$ & 0.03730 & 0.03730 \\
\hline 482 & 0.03730 & 0.09763 & $2.84 \mathrm{E}-06$ & 0.03730 & 0.03731 \\
\hline 483 & 0.03731 & 0.09763 & $2.84 \mathrm{E}-06$ & 0.03731 & 0.03731 \\
\hline 484 & 0.03731 & 0.09763 & $2.84 \mathrm{E}-06$ & 0.03731 & 0.03732 \\
\hline 485 & 0.03732 & 0.09763 & $2.83 \mathrm{E}-06$ & 0.03732 & 0.03732 \\
\hline 486 & 0.03732 & 0.09763 & $2.83 \mathrm{E}-06$ & 0.03732 & 0.03733 \\
\hline 487 & 0.03733 & 0.09763 & $2.82 \mathrm{E}-06$ & 0.03733 & 0.03733 \\
\hline 488 & 0.03734 & 0.09763 & $2.82 \mathrm{E}-06$ & 0.03733 & 0.03734 \\
\hline 489 & 0.03734 & 0.09763 & $2.84 \mathrm{E}-06$ & 0.03734 & 0.03734 \\
\hline 490 & 0.03735 & 0.09763 & $2.84 \mathrm{E}-06$ & 0.03734 & 0.03735 \\
\hline 491 & 0.03735 & 0.09763 & $2.84 \mathrm{E}-06$ & 0.03735 & 0.03735 \\
\hline 492 & 0.03736 & 0.09763 & $2.83 \mathrm{E}-06$ & 3735 & 0.03736 \\
\hline 493 & 0.03736 & 0.09763 & $2.83 \mathrm{E}-06$ & 0.03736 & 0.03736 \\
\hline 494 & 0.03737 & 0.09763 & $2.82 \mathrm{E}-06$ & 0.03736 & 0.03737 \\
\hline 495 & 0.03737 & 0.09763 & $2.82 \mathrm{E}-06$ & 0.03737 & 0.03737 \\
\hline 496 & 0.03738 & 0.09763 & $2.82 \mathrm{E}-06$ & 0.03737 & 0.03738 \\
\hline 497 & 0.03738 & 0.09763 & $2.81 \mathrm{E}-06$ & 0.03738 & 0.03739 \\
\hline 498 & 0.03739 & 0.09763 & 2.81E-06 & 0.03738 & 0.03739 \\
\hline 499 & 0.03739 & 0.09763 & $2.81 \mathrm{E}-06$ & 0.03739 & 0.03740 \\
\hline 500 & 0.03740 & 0.09763 & 2.80E-06 & 3740 & 3740 \\
\hline 501 & 0.03740 & 0.09763 & $2.80 \mathrm{E}-06$ & 0.03740 & 0.03741 \\
\hline 502 & 0.03741 & 0.09763 & $2.80 \mathrm{E}-06$ & 0.03741 & 0.03741 \\
\hline 503 & 0.03741 & 0.09763 & 2.79E-06 & 0.03741 & 0.03742 \\
\hline 504 & 0.03742 & 0.09763 & $2.80 \mathrm{E}-06$ & 0.03742 & 0.03742 \\
\hline 505 & 0.03742 & 0.09763 & $2.80 \mathrm{E}-06$ & 0.03742 & 0.03743 \\
\hline 506 & 0.03743 & 0.09763 & $2.80 \mathrm{E}-06$ & 0.03743 & 0.03743 \\
\hline 507 & 0.03743 & 0.09763 & $2.79 \mathrm{E}-06$ & 0.03743 & 0.03744 \\
\hline 508 & 0.03744 & 0.09763 & 2.79E-06 & 0.03744 & 0.03744 \\
\hline 509 & 0.03744 & 0.09763 & 2.79E-06 & 0.03744 & 0.03745 \\
\hline 510 & 0.03745 & 0.09763 & 2.79E-06 & 0.03745 & 0.03745 \\
\hline 511 & 0.03745 & 0.09763 & $2.78 \mathrm{E}-06$ & 0.03745 & 0.03746 \\
\hline 512 & 0.03746 & 0.09763 & $2.78 \mathrm{E}-06$ & 0.03746 & 0.03746 \\
\hline 513 & 0.03747 & 0.09763 & $2.78 \mathrm{E}-06$ & 0.03746 & 0.03747 \\
\hline 514 & 0.03747 & 0.09763 & 2.77E-06 & 0.03747 & 0.03747 \\
\hline 515 & 0.03748 & 0.09763 & 2.77E-06 & 0.03747 & 0.03748 \\
\hline 516 & 0.03748 & 0.09763 & 2.77E-06 & 0.03748 & 0.03748 \\
\hline 517 & 0.03749 & 0.09763 & $2.76 \mathrm{E}-06$ & 0.03748 & 0.03749 \\
\hline 518 & 0.03749 & 0.09763 & 2.77E-06 & 0.03749 & 0.03749 \\
\hline 519 & 0.03750 & 0.09763 & $2.80 \mathrm{E}-06$ & 0.03749 & 0.03750 \\
\hline 520 & 0.03750 & 0.09763 & $2.80 \mathrm{E}-06$ & 0.03750 & 0.03750 \\
\hline 521 & 0.03751 & 0.09763 & $2.80 \mathrm{E}-06$ & 0.03750 & 0.03751 \\
\hline 522 & 0.03751 & 0.09763 & 2.79E-06 & 0.03751 & 0.03751 \\
\hline 523 & 0.03752 & 0.09763 & 2.79E-06 & 0.03751 & 0.03752 \\
\hline 524 & 0.03752 & 0.09763 & 2.79E-06 & 0.03752 & 0.03752 \\
\hline 525 & 0.03753 & 0.09763 & 2.79E-06 & 0.03752 & 0.03753 \\
\hline 526 & 0.03753 & 0.09763 & $2.78 \mathrm{E}-06$ & 0.03753 & 0.03753 \\
\hline 527 & 0.03754 & 0.09763 & 2.79E-06 & 0.03753 & 0.03754 \\
\hline 528 & 0.03754 & 0.09763 & $2.81 \mathrm{E}-06$ & 0.03754 & 0.03755 \\
\hline
\end{tabular}




\begin{tabular}{|c|c|c|c|c|c|}
\hline $\mathrm{i}$ & $w(i)$ & $f(w(i))$ & $d(i)$ & $w(i)-d(i)$ & $w(i)+d$ \\
\hline 529 & 0.03755 & 0.09763 & $2.81 \mathrm{E}-06$ & 0.03754 & 0.03755 \\
\hline 530 & 0.03755 & 0.09763 & $2.80 \mathrm{E}-06$ & 0.03755 & 0.03756 \\
\hline 531 & 0.03756 & 0.09763 & $2.80 \mathrm{E}-06$ & 0.03756 & 0.03756 \\
\hline 532 & 0.03756 & 0.09763 & $2.80 \mathrm{E}-06$ & 0.03756 & 0.03757 \\
\hline 533 & 0.03757 & 0.09763 & $2.80 \mathrm{E}-06$ & 0.03757 & 0.03757 \\
\hline 534 & 0.03757 & 0.09763 & $2.80 \mathrm{E}-06$ & 0.03757 & 0.03758 \\
\hline 535 & 0.03758 & 0.09763 & 2.79E-06 & 0.03758 & 0.03758 \\
\hline 536 & 0.03758 & 0.09763 & $2.79 \mathrm{E}-06$ & 0.03758 & 0.03759 \\
\hline 537 & 0.03759 & 0.09763 & 2.79E-06 & 0.03759 & 0.03759 \\
\hline 538 & 0.03759 & 0.09763 & $2.79 \mathrm{E}-06$ & 0.03759 & 0.03760 \\
\hline 539 & 0.03760 & 0.09763 & $2.81 \mathrm{E}-06$ & 0.03760 & 0.03760 \\
\hline 540 & 0.03760 & 0.09763 & $2.81 \mathrm{E}-06$ & 0.03760 & 0.03761 \\
\hline 541 & 0.03761 & 0.09763 & $2.81 \mathrm{E}-06$ & 0.03761 & 0.03761 \\
\hline 542 & 0.03761 & 0.09763 & $2.81 \mathrm{E}-06$ & 0.03761 & 0.03762 \\
\hline 543 & 0.03762 & 0.09763 & 2.81E-06 & 0.03762 & 0.03762 \\
\hline 544 & 0.03763 & 0.09763 & 2.81E-06 & 0.03762 & 0.03763 \\
\hline 545 & 0.03763 & 0.09763 & $2.80 \mathrm{E}-06$ & 0.03763 & 0.03763 \\
\hline 546 & 0.03 & 0. & $2.80 \mathrm{E}-06$ & 763 & 764 \\
\hline 547 & 0.03764 & 0.09763 & $2.82 \mathrm{E}-06$ & 0.03764 & 0.03764 \\
\hline 548 & 0.03765 & 0.09763 & $2.86 \mathrm{E}-06$ & 0.03764 & 0.03765 \\
\hline 549 & 0.03765 & 0.09763 & $2.86 \mathrm{E}$ & 0.03765 & 765 \\
\hline 550 & 0.03766 & 0.09763 & $2.86 \mathrm{E}-06$ & 0.03765 & 0.03766 \\
\hline 551 & 0.03766 & 0.09763 & $2.86 \mathrm{E}-06$ & 0.03766 & 0.03766 \\
\hline 552 & 0.03767 & 0.09763 & $2.86 \mathrm{E}-06$ & 0.03766 & 0.03767 \\
\hline 553 & 0.03767 & 0.09763 & $2.86 \mathrm{E}-06$ & 0.03767 & 0.03768 \\
\hline 554 & 0.03768 & 0.09763 & $2.86 \mathrm{E}-06$ & 0.03767 & 0.03768 \\
\hline 555 & 0.03768 & 0.09763 & $2.85 \mathrm{E}-06$ & 0.03768 & 0.03769 \\
\hline 556 & 0.03769 & 0.09763 & $2.85 \mathrm{E}-06$ & 0.03769 & 0.03769 \\
\hline 557 & 0.03769 & 0.09763 & $2.85 \mathrm{E}-06$ & 0.03769 & 0.03770 \\
\hline 558 & 0.03770 & 0.09763 & $2.85 \mathrm{E}-06$ & 0.03770 & 0.03770 \\
\hline 559 & 0.03770 & 0.09763 & $2.85 \mathrm{E}-06$ & 0.03770 & 0.03771 \\
\hline 560 & 0.03771 & 0.09763 & $2.85 \mathrm{E}-06$ & 0.03771 & 0.03771 \\
\hline 561 & 0.03771 & 0.09763 & $2.85 \mathrm{E}-06$ & 0.03771 & 0.03772 \\
\hline 562 & 0.03772 & 0.09763 & $2.85 \mathrm{E}-06$ & 0.03772 & 0.03772 \\
\hline 563 & 0.03773 & 0.09763 & $2.85 \mathrm{E}-06$ & 0.03772 & 0.03773 \\
\hline 564 & 0.03773 & 0.09763 & $2.85 \mathrm{E}-06$ & 0.03773 & 0.03773 \\
\hline 565 & 0.03774 & 0.09763 & $2.85 \mathrm{E}-06$ & 0.03773 & 0.03774 \\
\hline 566 & 0.03774 & 0.09763 & $2.85 \mathrm{E}-06$ & 0.03774 & 0.03774 \\
\hline 567 & 0.03775 & 0.09763 & $2.85 \mathrm{E}-06$ & 0.03774 & 0.03775 \\
\hline 568 & 0.03775 & 0.09763 & $2.84 \mathrm{E}-06$ & 0.03775 & 0.03775 \\
\hline 569 & 0.03776 & 0.09763 & $2.84 \mathrm{E}-06$ & 0.03775 & 0.03776 \\
\hline 570 & 0.03776 & 0.09763 & $2.84 \mathrm{E}-06$ & 0.03776 & 0.03777 \\
\hline 571 & 0.03777 & 0.09763 & $2.84 \mathrm{E}-06$ & 0.03776 & 0.03777 \\
\hline 572 & 0.03777 & 0.09763 & $2.84 \mathrm{E}-06$ & 0.03777 & 0.03778 \\
\hline 573 & 0.03778 & 0.09763 & $2.84 \mathrm{E}-06$ & 0.03778 & 0.03778 \\
\hline 574 & 0.03778 & 0.09763 & $2.84 \mathrm{E}-06$ & 0.03778 & 0.03779 \\
\hline 575 & 0.03779 & 0.09763 & $2.84 \mathrm{E}-06$ & 0.03779 & 0.03779 \\
\hline 576 & 0.03779 & 0.09763 & $2.84 \mathrm{E}-06$ & 0.03779 & 0.03780 \\
\hline
\end{tabular}




\begin{tabular}{|c|c|c|c|c|c|}
\hline $\mathrm{i}$ & $w(i)$ & $f(w(i))$ & $d(i)$ & $w(i)-d(i)$ & $w(i)+d$ \\
\hline 577 & 0.03780 & 0.09763 & $2.84 \mathrm{E}-06$ & 0.03780 & 0.03780 \\
\hline 578 & 0.03780 & 0.09763 & $2.84 \mathrm{E}-06$ & 0.03780 & 0.03781 \\
\hline 579 & 0.03781 & 0.09763 & $2.84 \mathrm{E}-06$ & 0.03781 & 0.03781 \\
\hline 580 & 0.03781 & 0.09763 & $2.84 \mathrm{E}-06$ & 0.03781 & 0.03782 \\
\hline 581 & 0.03782 & 0.09763 & $2.84 \mathrm{E}-06$ & 0.03782 & 0.03782 \\
\hline 582 & 0.03783 & 0.09763 & $2.84 \mathrm{E}-06$ & 0.03782 & 0.03783 \\
\hline 583 & 0.03783 & 0.09763 & $2.84 \mathrm{E}-06$ & 0.03783 & 0.03783 \\
\hline 584 & 0.03784 & 0.09763 & $2.84 \mathrm{E}-06$ & 0.03783 & 0.03784 \\
\hline 585 & 0.03784 & 0.09763 & 2.91E-06 & 0.03784 & 0.03784 \\
\hline 586 & 0.03785 & 0.09763 & $2.96 \mathrm{E}-06$ & 0.03784 & 0.03785 \\
\hline 587 & 0.03785 & 0.09763 & $2.96 \mathrm{E}-06$ & 0.03785 & 0.03785 \\
\hline 588 & 0.03786 & 0.09763 & $2.96 \mathrm{E}-06$ & 0.03785 & 0.03786 \\
\hline 589 & 0.03786 & 0.09763 & $2.96 \mathrm{E}-06$ & 0.03786 & 0.03787 \\
\hline 590 & 0.03787 & 0.09763 & $2.96 \mathrm{E}-06$ & 0.03787 & 0.03787 \\
\hline 591 & 0.03787 & 0.09763 & $2.97 \mathrm{E}-06$ & 0.03787 & 788 \\
\hline 592 & 0.03788 & 0.09763 & $3.40 \mathrm{E}-06$ & 0.03788 & 0.03788 \\
\hline 593 & 0.03789 & 0.09763 & $3.48 \mathrm{E}-06$ & 0.03788 & 0.03789 \\
\hline 594 & 0.0 & 0. & 6 & 789 & 790 \\
\hline 595 & 0.03790 & 0.09763 & $3.56 \mathrm{E}-06$ & 0.03790 & 0.03790 \\
\hline 596 & 0.03791 & 0.09763 & 3.57E-06 & 0.03790 & 0.03791 \\
\hline 597 & 0.03791 & 0.09763 & & 791 & \\
\hline 598 & 0.03792 & 0.09763 & $3.58 \mathrm{E}-06$ & 0.03791 & 0.03792 \\
\hline 599 & 0.03793 & 0.09763 & 4.27E-06 & 0.03792 & 0.03793 \\
\hline 600 & 0.03793 & 0.09763 & $8.65 \mathrm{E}-06$ & 0.03792 & 0.03794 \\
\hline 601 & 0.03795 & 0.09763 & 8.71E-06 & 0.03794 & 0.03796 \\
\hline 602 & 0.03797 & 0.09763 & 8.77E-06 & 0.03796 & 0.03797 \\
\hline 603 & 0.03798 & 0.09763 & $8.81 \mathrm{E}-06$ & 0.03797 & 0.03799 \\
\hline 604 & 0.03800 & 0.09763 & $8.88 \mathrm{E}-06$ & 0.03799 & 0.03801 \\
\hline 605 & 0.03801 & 0.09763 & 8.93E-06 & 0.03801 & 0.03802 \\
\hline 606 & 0.03803 & 0.09763 & 8.98E-06 & 0.03802 & 0.03804 \\
\hline 607 & 0.03805 & 0.09763 & $9.03 E-06$ & 0.03804 & 0.03806 \\
\hline 608 & 0.03806 & 0.09763 & $9.13 \mathrm{E}-06$ & 0.03805 & 0.03807 \\
\hline 609 & 0.03808 & 0.09763 & $9.18 \mathrm{E}-06$ & 0.03807 & 0.03809 \\
\hline 610 & 0.03810 & 0.09763 & $9.24 \mathrm{E}-06$ & 0.03809 & 0.03811 \\
\hline 611 & 0.03811 & 0.09763 & $9.29 \mathrm{E}-06$ & 0.03811 & 0.03812 \\
\hline 612 & 0.03813 & 0.09763 & 9.34E-06 & 0.03812 & 0.03814 \\
\hline 613 & 0.03815 & 0.09763 & $9.40 \mathrm{E}-06$ & 0.03814 & 0.03816 \\
\hline 614 & 0.03817 & 0.09763 & $9.45 \mathrm{E}-06$ & 0.03816 & 0.03818 \\
\hline 615 & 0.03818 & 0.09763 & 9.51E-06 & 0.03817 & 0.03819 \\
\hline 616 & 0.03820 & 0.09763 & 9.57E-06 & 0.03819 & 0.03821 \\
\hline 617 & 0.03822 & 0.09763 & 9.71E-06 & 0.03821 & 0.03823 \\
\hline 618 & 0.03824 & 0.09763 & $9.98 \mathrm{E}-06$ & 0.03823 & 0.03825 \\
\hline 619 & 0.03826 & 0.09763 & $1.01 \mathrm{E}-05$ & 0.03825 & 0.03827 \\
\hline 620 & 0.03827 & 0.09763 & $1.02 \mathrm{E}-05$ & 0.03826 & 0.03828 \\
\hline 621 & 0.03829 & 0.09763 & $1.03 \mathrm{E}-05$ & 0.03828 & 0.03830 \\
\hline 622 & 0.03831 & 0.09763 & $1.04 \mathrm{E}-05$ & 0.03830 & 0.03832 \\
\hline 623 & 0.03833 & 0.09763 & $1.05 \mathrm{E}-05$ & 0.03832 & 0.03834 \\
\hline 624 & 0.03835 & 0.09763 & $1.06 \mathrm{E}-05$ & 0.03834 & 0.03836 \\
\hline
\end{tabular}




\begin{tabular}{|c|c|c|c|c|c|}
\hline $\mathrm{i}$ & $w(i)$ & $f(w(i))$ & $d(i)$ & $w(i)-d(i)$ & $w(i)+d(i)$ \\
\hline 625 & 0.03837 & 0.09763 & $1.07 \mathrm{E}-05$ & 0.03836 & 0.03838 \\
\hline 626 & 0.03839 & 0.09763 & $1.08 \mathrm{E}-05$ & 0.03838 & 0.03840 \\
\hline 627 & 0.03841 & 0.09763 & $1.11 \mathrm{E}-05$ & 0.03840 & 0.03842 \\
\hline 628 & 0.03843 & 0.09763 & $1.16 \mathrm{E}-05$ & 0.03842 & 0.03844 \\
\hline 629 & 0.03845 & 0.09763 & $1.18 \mathrm{E}-05$ & 0.03844 & 0.03846 \\
\hline 630 & 0.03847 & 0.09763 & $1.20 \mathrm{E}-05$ & 0.03846 & 0.03849 \\
\hline 631 & 0.03850 & 0.09763 & $1.21 \mathrm{E}-05$ & 0.03848 & 0.03851 \\
\hline 632 & 0.03852 & 0.09763 & $1.23 \mathrm{E}-05$ & 0.03851 & 0.03853 \\
\hline 633 & 0.03854 & 0.09763 & $1.24 \mathrm{E}-05$ & 0.03853 & 0.03855 \\
\hline 634 & 0.03857 & 0.09763 & $1.27 \mathrm{E}-05$ & 0.03855 & 0.03858 \\
\hline 635 & 0.03859 & 0.09763 & $1.28 \mathrm{E}-05$ & 0.03858 & 0.03860 \\
\hline 636 & 0.03861 & 0.09763 & 1.30E-05 & 0.03860 & 0.03863 \\
\hline 637 & 0.03864 & 0.09763 & $1.32 \mathrm{E}-05$ & 0.03862 & 0.03865 \\
\hline 638 & 0.03866 & 0.09763 & $1.34 \mathrm{E}-05$ & 0.03865 & 0.03867 \\
\hline 639 & 0.03869 & 0.09763 & $1.36 \mathrm{E}-05$ & 0.03867 & 3870 \\
\hline 640 & 0.03871 & 0.09763 & 1.37E-05 & 0.03870 & 0.03872 \\
\hline 641 & 0.03874 & 0.09763 & 1.39E-05 & 0.03872 & 0.03875 \\
\hline 642 & $0.03 \varepsilon$ & 0.0 & & 375 & \\
\hline 643 & 0.03879 & 0.09763 & $1.44 \mathrm{E}-05$ & 0.03877 & 0.03880 \\
\hline 644 & 0.03881 & 0.09763 & $1.46 \mathrm{E}-05$ & 0.03880 & 0.03883 \\
\hline 645 & 0.03884 & 0.09763 & $1.48 \mathrm{E}$ & 0.03883 & 0.03886 \\
\hline 646 & 0.03887 & 0.09763 & $1.50 \mathrm{E}-05$ & 0.03885 & 0.03888 \\
\hline 647 & 0.03890 & 0.09763 & $1.52 \mathrm{E}-05$ & 0.03888 & 0.03891 \\
\hline 648 & 0.03892 & 0.09763 & $1.55 \mathrm{E}-05$ & 0.03891 & 0.03894 \\
\hline 649 & 0.03895 & 0.09763 & $1.57 \mathrm{E}-05$ & 0.03894 & 0.03897 \\
\hline 650 & 0.03898 & 0.09762 & $1.60 \mathrm{E}-05$ & 0.03897 & 0.03900 \\
\hline 651 & 0.03901 & 0.09762 & $1.62 \mathrm{E}-05$ & 0.03900 & 0.03903 \\
\hline 652 & 0.03904 & 0.09762 & $1.65 \mathrm{E}-05$ & 0.03903 & 0.03906 \\
\hline 653 & 0.03907 & 0.09762 & $1.67 \mathrm{E}-05$ & 0.03906 & 0.03909 \\
\hline 654 & 0.03910 & 0.09762 & 1.70E-05 & 0.03909 & 0.03912 \\
\hline 655 & 0.03913 & 0.09762 & $1.72 \mathrm{E}-05$ & 0.03912 & 0.03915 \\
\hline 656 & 0.03917 & 0.09762 & $1.75 \mathrm{E}-05$ & 0.03915 & 0.03918 \\
\hline 657 & 0.03920 & 0.09762 & $1.78 \mathrm{E}-05$ & 0.03918 & 0.03922 \\
\hline 658 & 0.03923 & 0.09762 & $1.81 \mathrm{E}-05$ & 0.03921 & 0.03925 \\
\hline 659 & 0.03927 & 0.09762 & $1.84 \mathrm{E}-05$ & 0.03925 & 0.03928 \\
\hline 660 & 0.03930 & 0.09762 & $1.87 \mathrm{E}-05$ & 0.03928 & 0.03932 \\
\hline 661 & 0.03933 & 0.09762 & $1.90 \mathrm{E}-05$ & 0.03932 & 0.03935 \\
\hline 662 & 0.03937 & 0.09762 & $1.93 \mathrm{E}-05$ & 0.03935 & 0.03939 \\
\hline 663 & 0.03940 & 0.09762 & $1.96 \mathrm{E}-05$ & 0.03939 & 0.03942 \\
\hline 664 & 0.03944 & 0.09762 & $1.99 \mathrm{E}-05$ & 0.03942 & 0.03946 \\
\hline 665 & 0.03948 & 0.09762 & $2.02 \mathrm{E}-05$ & 0.03946 & 0.03950 \\
\hline 666 & 0.03952 & 0.09762 & $2.06 \mathrm{E}-05$ & 0.03949 & 0.03954 \\
\hline 667 & 0.03955 & 0.09762 & $2.11 \mathrm{E}-05$ & 0.03953 & 0.03957 \\
\hline 668 & 0.03959 & 0.09762 & $2.14 \mathrm{E}-05$ & 0.03957 & 0.03961 \\
\hline 669 & 0.03963 & 0.09762 & $2.18 \mathrm{E}-05$ & 0.03961 & 0.03965 \\
\hline 670 & 0.03967 & 0.09762 & $2.23 \mathrm{E}-05$ & 0.03965 & 0.03969 \\
\hline 671 & 0.03971 & 0.09762 & $2.26 \mathrm{E}-05$ & 0.03969 & 0.03974 \\
\hline 672 & 0.03976 & 0.09762 & $2.30 \mathrm{E}-05$ & 0.03973 & 0.03978 \\
\hline
\end{tabular}




\begin{tabular}{|c|c|c|c|c|c|}
\hline i & $w(i)$ & $f(w(i))$ & $d(i)$ & $w(i)-d(i)$ & $w(i)+d(i)$ \\
\hline 673 & 0.03980 & 0.09762 & $2.36 \mathrm{E}-05$ & 0.03977 & 0.03982 \\
\hline 674 & 0.03984 & 0.09762 & $2.41 \mathrm{E}-05$ & 0.03982 & 0.03987 \\
\hline 675 & 0.03989 & 0.09762 & $2.45 \mathrm{E}-05$ & 0.03986 & 0.03991 \\
\hline 676 & 0.03993 & 0.09762 & $2.50 \mathrm{E}-05$ & 0.03991 & 0.03996 \\
\hline 677 & 0.03998 & 0.09762 & $2.56 \mathrm{E}-05$ & 0.03995 & 0.04000 \\
\hline 678 & 0.04003 & 0.09762 & $2.61 \mathrm{E}-05$ & 0.04000 & 0.04005 \\
\hline 679 & 0.04007 & 0.09762 & 2.67E-05 & 0.04005 & 0.04010 \\
\hline 680 & 0.04012 & 0.09762 & $2.72 \mathrm{E}-05$ & 0.04010 & 0.04015 \\
\hline 681 & 0.04017 & 0.09762 & $2.78 \mathrm{E}-05$ & 0.04015 & 0.04020 \\
\hline 682 & 0.04022 & 0.09762 & $2.84 \mathrm{E}-05$ & 0.04020 & 0.04025 \\
\hline 683 & 0.04028 & 0.09762 & 2.91E-05 & 0.04025 & 0.04031 \\
\hline 684 & 0.04033 & 0.09762 & 2.97E-05 & 0.04030 & 0.04036 \\
\hline 685 & 0.04039 & 0.09762 & 3.03E-05 & 0.04036 & 0.04042 \\
\hline 686 & 0.04044 & 0.09762 & $3.10 \mathrm{E}-05$ & 0.04041 & 0.04047 \\
\hline 687 & 0.04050 & 0.09762 & $3.23 \mathrm{E}-05$ & 0.04047 & 0.04053 \\
\hline 688 & 0.04056 & 0.09762 & 3.30E-05 & 0.04053 & 0.04059 \\
\hline 689 & 0.04062 & 0.09762 & 3.37E-05 & 0.04059 & 0.04065 \\
\hline 690 & 0.04068 & 0.09762 & $3.45 \mathrm{E}-05$ & 0.04065 & 0.04072 \\
\hline 691 & 0.04075 & 0.09762 & 3.53E-05 & 0.04071 & 0.04078 \\
\hline 692 & 0.04081 & 0.0 & $3.62 \mathrm{E}-05$ & 4078 & 4085 \\
\hline 693 & 0.04088 & 0.09762 & 3.69E-05 & 0.04084 & 0.04092 \\
\hline 694 & 0.04095 & 0.09762 & 3.79E-05 & 0.04091 & 0.04099 \\
\hline 695 & 0.04102 & 0.09762 & 3.89E-05 & 0.04098 & 4106 \\
\hline 696 & 0.04109 & 0.09762 & 3.99E-05 & 0.04105 & 0.04113 \\
\hline 697 & 0.04116 & 0.09762 & 4.10E-05 & 0.04112 & 0.04120 \\
\hline 698 & 0.04124 & 0.09762 & 4.2 & 04120 & .04128 \\
\hline 699 & 0.04132 & 0.09762 & $4.33 \mathrm{E}-05$ & 0.04127 & 0.04136 \\
\hline 700 & 0.04140 & 0.09762 & 4.45E-05 & 0.04135 & 0.04144 \\
\hline 701 & 0.04148 & 0.09762 & 4.57E-05 & 0.04143 & 0.04152 \\
\hline 702 & 0.04156 & 0.09762 & 4.70E-05 & 0.04152 & 0.04161 \\
\hline 703 & 0.04165 & 0.09761 & $4.83 \mathrm{E}-05$ & 0.04160 & 0.04170 \\
\hline 704 & 0.04174 & 0.09761 & 4.97E-05 & 0.04169 & 0.04179 \\
\hline 705 & 0.04183 & 0.09761 & $5.12 \mathrm{E}-05$ & 0.04178 & 0.04188 \\
\hline 706 & 0.04193 & 0.09761 & 5.27E-05 & 0.04187 & 0.04198 \\
\hline 707 & 0.04202 & 0.09761 & 5.43E-05 & 0.04197 & 0.04208 \\
\hline 708 & 0.04212 & 0.09761 & $5.62 \mathrm{E}-05$ & 0.04207 & 0.04218 \\
\hline 709 & 0.04223 & 0.09761 & $5.82 \mathrm{E}-05$ & 0.04217 & 0.04229 \\
\hline 710 & 0.04234 & 0.09761 & $6.01 \mathrm{E}-05$ & 0.04228 & 0.04240 \\
\hline 711 & 0.04245 & 0.09761 & $6.20 \mathrm{E}-05$ & 0.04239 & 0.04251 \\
\hline 712 & 0.04256 & 0.09761 & $6.42 \mathrm{E}-05$ & 0.04250 & 0.04263 \\
\hline 713 & 0.04268 & 0.09761 & $6.64 \mathrm{E}-05$ & 0.04261 & 0.04275 \\
\hline 714 & 0.04280 & 0.09761 & 6.87E-05 & 0.04274 & 0.04287 \\
\hline 715 & 0.04293 & 0.09761 & $7.10 \mathrm{E}-05$ & 0.04286 & 0.04300 \\
\hline 716 & 0.04306 & 0.09761 & 7.35E-05 & 0.04299 & 0.04314 \\
\hline 717 & 0.04320 & 0.09761 & 7.60E-05 & 0.04312 & 0.04327 \\
\hline 718 & 0.04334 & 0.09760 & $7.89 \mathrm{E}-05$ & 0.04326 & 0.04342 \\
\hline 719 & 0.04348 & 0.09760 & 8.17E-05 & 0.04340 & 0.04357 \\
\hline 720 & 0.04364 & 0.09760 & 8.47E-05 & 0.04355 & 0.04372 \\
\hline
\end{tabular}




\begin{tabular}{|c|c|c|c|c|c|}
\hline i & $w(i)$ & $f(w(i))$ & $d(i)$ & $w(i)-d(i)$ & $w(i)+d(i)$ \\
\hline 721 & 04379 & .09760 & $82 \mathrm{E}-05$ & 0.04370 & 0.04388 \\
\hline 722 & 0.04396 & 0.09760 & $9.18 \mathrm{E}-05$ & 4386 & 1405 \\
\hline 723 & 0.04413 & 0.09760 & $9.56 \mathrm{E}-05$ & 0.04403 & 0.04422 \\
\hline 724 & 0.04430 & 0.09760 & 9.95E-05 & 0.04420 & 0.04440 \\
\hline 725 & 0.04449 & 0.09760 & $1.04 \mathrm{E}-04$ & 0.04438 & 0.04459 \\
\hline 726 & 0.04468 & 0.09760 & 1.09E-04 & 0.04457 & 0.04479 \\
\hline 727 & 0.04488 & 0.09759 & $1.13 \mathrm{E}-04$ & 0.04477 & 0.04499 \\
\hline 728 & 0.04509 & 0.09759 & 1.19E-04 & 0.04497 & 4521 \\
\hline 729 & 0.04531 & 0.09759 & $1.24 \mathrm{E}-04$ & 0.04518 & 4543 \\
\hline 730 & 0.04554 & 0.09759 & $1.29 \mathrm{E}-04$ & 0.04541 & 0.04567 \\
\hline 731 & 0.04578 & 0.09759 & 1.35E-04 & 0.04564 & 0. \\
\hline 732 & 03 & 758 & 04 & 588 & 17 \\
\hline 733 & 0.04629 & 0.09758 & 1.49E-04 & 0.04614 & 0.04644 \\
\hline 734 & 0.04657 & 0.09758 & -04 & 641 & 0.0 \\
\hline 735 & 0.04685 & 0.09758 & 1. & 569 & 0. \\
\hline 736 & 0.04716 & 0.09758 & $1.72 \mathrm{E}-04$ & 0.04698 & 0.04733 \\
\hline 737 & 0.04748 & 0.09757 & -04 & 729 & 0 \\
\hline 738 & 0.04781 & 0.09757 & $1.92 \mathrm{E}-04$ & 0.04762 & 0.0 \\
\hline 739 & 0.04817 & 0.09757 & $2.03 \mathrm{E}-04$ & 0.04797 & 0.04837 \\
\hline 740 & 0.04854 & 0.09756 & -04 & 333 & 876 \\
\hline 741 & 0.04895 & 0.09756 & $2.34 \mathrm{E}-04$ & 0.04871 & 0.0 \\
\hline 742 & 0.04938 & 0.09755 & 2.49E-04 & 0.04913 & 0.04963 \\
\hline 743 & 84 & 0.09755 & $2.65 \mathrm{E}-04$ & 0.04957 & 011 \\
\hline 744 & 0.05033 & 0.09754 & $2.84 \mathrm{E}-04$ & 0.05005 & 0.05062 \\
\hline 745 & 0.05086 & 0.09753 & 3.07E-04 & 0.05055 & 0.05116 \\
\hline 746 & 43 & 0.09752 & $\mathrm{E}-04$ & 110 & 176 \\
\hline 747 & 0.05204 & 0.09752 & 3.59E-04 & 168 & \\
\hline 748 & 0.05270 & 0.09751 & $3.88 \mathrm{E}-04$ & 0.05231 & 0.05309 \\
\hline 749 & 0.05342 & 0.09750 & $4.22 \mathrm{E}-04$ & 500 & 384 \\
\hline 750 & 0.05420 & 0.09748 & 4.60E-04 & 374 & 5466 \\
\hline 751 & 0.05505 & 0.09747 & 5.04E-04 & 0.05455 & 0.05556 \\
\hline 752 & 0.05598 & 0.09745 & $5.56 \mathrm{E}-04$ & 0.05543 & 0.05654 \\
\hline 753 & 0.05701 & 0.09743 & $6.15 \mathrm{E}-04$ & 0.05640 & 0.05763 \\
\hline 754 & 0.05815 & 0.09741 & 6.83E-04 & 0.05747 & 0.05883 \\
\hline 755 & 0.05941 & 0.09739 & 7.64E-04 & 0.05865 & 0.06018 \\
\hline 756 & 0.06083 & 0.09736 & 8.60E-04 & 0.05997 & 0.06169 \\
\hline 757 & 0.06242 & 0.09732 & $9.74 \mathrm{E}-04$ & 0.06144 & 0.06339 \\
\hline 758 & 0.06422 & 0.09728 & $1.11 \mathrm{E}-03$ & 0.06311 & 0.06533 \\
\hline 759 & 0.06627 & 0.09722 & $1.28 \mathrm{E}-03$ & 0.06499 & 0.06755 \\
\hline 760 & 0.06864 & 0.09716 & 1.49E-03 & 0.06715 & 0.07012 \\
\hline 761 & 0.07139 & 0.09707 & $1.75 \mathrm{E}-03$ & 0.06964 & 0.07313 \\
\hline 762 & 0.07462 & 0.09697 & $2.08 \mathrm{E}-03$ & 0.07254 & 0.07670 \\
\hline 763 & 0.07847 & 0.09683 & $2.51 \mathrm{E}-03$ & 0.07595 & 0.08098 \\
\hline 764 & 0.08312 & 0.09665 & 3.10E-03 & 0.08002 & 0.08622 \\
\hline 765 & 0.08885 & 0.09639 & 3.89E-03 & 0.08496 & 0.09274 \\
\hline 766 & 0.09605 & 0.09603 & $5.02 \mathrm{E}-03$ & 0.09103 & 0.10107 \\
\hline 767 & 0.10533 & 0.09551 & 6.67E-03 & 0.09866 & 0.11200 \\
\hline 768 & 0.11766 & 0.09491 & 8.57E-03 & 0.10909 & 0.12623 \\
\hline
\end{tabular}




\begin{tabular}{|c|c|c|c|c|c|}
\hline $\mathrm{i}$ & $w(i)$ & $f(w(i))$ & $d(i)$ & $w(i)-d(i)$ & $w(i)+d(i)$ \\
\hline 769 & 0.13351 & 0.09386 & $1.19 E-02$ & 0.12165 & 0.14537 \\
\hline 770 & 0.15545 & 0.09161 & $1.89 E-02$ & 0.13651 & 0.17439 \\
\hline 771 & 0.19049 & 0.08886 & $2.76 E-02$ & 0.16290 & 0.21808 \\
\hline 772 & 0.24153 & 0.08769 & $3.13 E-02$ & 0.21028 & 0.27279 \\
\hline
\end{tabular}

